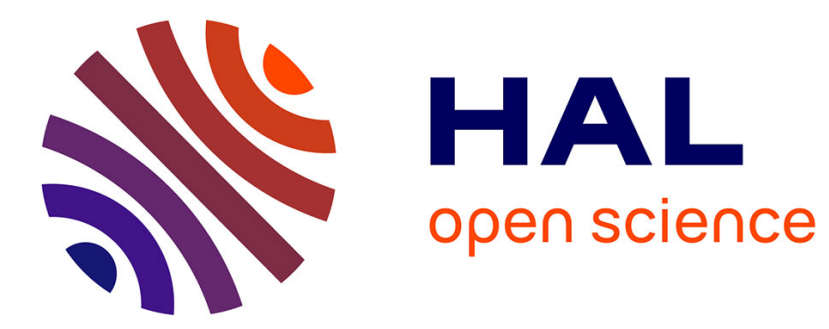

\title{
Diagrams in the theory of differential equations (eighteenth to nineteenth centuries)
}

Dominique Tournès

\section{To cite this version:}

Dominique Tournès. Diagrams in the theory of differential equations (eighteenth to nineteenth centuries). Synthese, 2012, 186 (1), pp.257-288. 10.1007/s11229-012-0069-z . hal-01186149

\section{HAL Id: hal-01186149 \\ https://hal.univ-reunion.fr/hal-01186149}

Submitted on 13 Apr 2020

HAL is a multi-disciplinary open access archive for the deposit and dissemination of scientific research documents, whether they are published or not. The documents may come from teaching and research institutions in France or abroad, or from public or private research centers.
L'archive ouverte pluridisciplinaire HAL, est destinée au dépôt et à la diffusion de documents scientifiques de niveau recherche, publiés ou non, émanant des établissements d'enseignement et de recherche français ou étrangers, des laboratoires publics ou privés.

\section{(이) $\$$}

Distributed under a Creative Commons Attribution - NonCommercial - NoDerivatives $\mid 4.0$ 


\title{
Diagrams in the theory of differential equations (eighteenth to nineteenth centuries)
}

\author{
Dominique Tournès
}

Received: 1 October 2009 / Accepted: 1 July 2010 / Published online: 10 February 2012

(C) Springer Science+Business Media B.V. 2012

\begin{abstract}
Diagrams have played an important role throughout the entire history of differential equations. Geometrical intuition, visual thinking, experimentation on diagrams, conceptions of algorithms and instruments to construct these diagrams, heuristic proofs based on diagrams, have interacted with the development of analytical abstract theories. We aim to analyze these interactions during the two centuries the classical theory of differential equations was developed. They are intimately connected to the difficulties faced in defining what the solution of a differential equation is and in describing the global behavior of such a solution.
\end{abstract}

Keywords Differential equation · Diagram - Geometric intuition · Visual thinking · Integral curve · Tractional motion · Qualitative integration · Graphical integration

\section{Introduction}

Philosophers have extensively studied the role of diagrams in the foundations of mathematics, for example, geometrical diagrams in Euclid's Elements ${ }^{1}$ and Euler-Venn's diagrams in logic (Shin 1994). This research has clearly highlighted situations in which the diagram not only had an illustrative or heuristic function but also was closely allied to the discursive text, or even could be substituted for it to ensure the rigor of

\footnotetext{
1 Dozens of papers have been written on this subject. Among the most recent are Panza (2007), Manders (2008) and Mumma (2009). All three contain numerous references to previous important works.

D. Tournès $(\bowtie)$

LIM, EA 2525, University of La Réunion, Saint-Denis, France

e-mail: dominique.tournes@univ-reunion.fr

D. Tournès

SPHERE, UMR 7219, CNRS, University Paris Diderot, Paris, France
} 
reasoning. It also clarified the two kinds of visualization in mathematics: visualization via pictures drawn on paper on the one hand, via mental images on the other (Mancosu 2005).

There has been less interest in the place of diagrams in the development of calculus and function theory. One can hardly cite Giaquinto's paper (1994) about results of elementary analysis as Rolle's theorem or Bolzano's theorem. In this paper, Giaquinto showed that it was difficult to acquire a satisfactory visualization of a continuous or differentiable function, and that the role of diagrams was becoming more complex as soon as the limit of an infinite process occurs. Therefore it seemed to me interesting to attempt a similar study about ordinary differential equations, especially since the historians, as far as they are concerned, do not seem to have paid any attention to this issue. The classical articles of the Encyclopédie des sciences mathématiques pures et appliquées (Painlevé and Vessiot 1910) present a logical, analytical and purely linguistic development of the theory, in which diagrams have no role. This is practically the same thing for the most recent panoramas of the history of differential equations (Kolmogorov and Yushkevich 1998; Archibald 2003).

So, where and how did diagrams appear in the theory of differential equations? What was their role in the development and applications of this domain? To avoid an excessively broad topic, I chose to limit myself to eighteenth and nineteenth centuries, in other words to what I am tempted to call the "classical theory" of differential equations. Of course, it would have been interesting to take things from the beginning, starting from Debeaune's problems and continuing up to Newton, Leibniz and Bernoulli's fundamental works. In this initial stage, in which mathematicians were working with imprecise concepts in a mainly geometrical context, diagrams necessarily played an essential role, but a paper covering it would have been too long. The same is true for the twentieth century, in which diagrams again occupy an important place, in the considerable developments in the qualitative study of dynamical systems and in the numerical analysis of differential equations.

I will therefore consider the period that begins with Gabriele Manfredi's famous treatise of 1707, which was the first monograph ever to be dedicated to differential equations, and that ends with Émile Picard's Traité d'analyse (1893-1896), which contains a broad synthesis of all that was known about the subject in the late nineteenth century. Picard's treatise marks rather precisely the instant when the theory of differential equations attains its adulthood: it has acquired a solid foundation from which it develops simultaneously according to the algebraic, analytical and qualitative points of view (Gilain 1994, p. 450). I will aim to track throughout this period (1700-1900) the constitutive role of diagrams in the theory of differential equations in the field of real numbers. In this context, solutions of equations are indeed represented by curves in the plane. We can thus observe natural and frequent interventions of diagrams.

\section{An overview of two centuries of diagrams}

Between Manfredi and Picard, I chose a dozen books or memoirs, which cover the period well and seem particularly significant to me. These texts are either synthetic 
treatises that had a particular influence in education and among scholars, or works that contain important theoretical advances. The following table provides, for each of these publications, the number of diagrams that illustrate the part of the text dealing with differential equations.

\begin{tabular}{lc}
\hline Book or memoir & Number of diagrams \\
\hline Manfredi 1707 & 35 \\
Agnesi 1748 & 8 \\
Riccati 1752 & 16 \\
Bougainville 1756 & 8 \\
Euler 1768-1769 & 0 \\
Lacroix 1798 & 11 \\
Cauchy 1824 & 0 \\
Moigno 1844 & 0 \\
Boole 1859 & 4 \\
Lipschitz 1880 & 0 \\
Poincaré 1881-1886 & 31 \\
Picard 1893-1896 & 14 \\
\hline
\end{tabular}

By examining the number and function of these diagrams, we find three major, wellknown periods in the theory of differential equations. Let us say some words about that to fix the general context before proceeding to a detailed study of some particularly significant diagrams.

Until 1750, the framework of the theory is geometric. The aim is to solve the inverse tangent problem-i.e. to construct a curve the tangents of which satisfy a given property. New curves appear in many applications which do not fall into the class of algebraic curves accepted in geometry since Descartes, and there is a strong desire to legitimize them (Bos 1988, p. 24). As the primary object of the theory is a curve to be defined and drawn, it is natural to find numerous diagrams in the first treatises: this is the case up to de Bougainville (1756). To construct these curves by points, one first tried to find equations in a finite form, by accepting as legitimate operations the algebraic operations and the quadrature of curves: this was called "integration by quadratures". From this Cartesian perspective, algebra is primarily a tool of analysis conceived to serve geometry. This way of thinking is, for example, still present in Vincenzo Riccati's memoir of 1752 when, after solving a differential equation by quadratures, the author writes: "A construction takes its source in this analysis". ${ }^{2}$ Here, the equation is still only a way to obtain the curve; it is not a goal in itself.

But gradually throughout the first half of the eighteenth century, mathematicians become aware that the equation can be considered as a definition of the curve and that one can work directly on the equation without actually trying to describe the curve. By 1750, it is time for a fundamental change in mathematics: ancient geometric thought gives way to modern algebraic thought. One does not try to construct curves any more, one studies functions. By this new approach, differential equations do not require immediate geometric representation; mathematicians think directly about

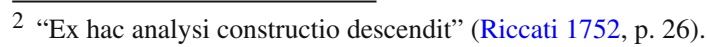


solving and classifying them (Guicciardini 1994, p. 314). Solutions of equations are now represented by algebraic algorithms, finite or infinite, like series or continued fractions. An algebraic expression acquires legitimacy on its own. There is no need to return to geometry to give it sense. Mathematicians, in search of an algebra of the infinite liberated from geometry and mechanics, move radically to purely analytical methods of investigation.

Already, in the books of Agnesi (1748) and de Bougainville (1756), there are fewer diagrams, and they play a less central role. This algebraization, however, reaches its peak with Euler (1768-1769) who writes the first calculus treatise without any diagrams. This is the triumph of algebraic analysis: Euler's style is characterized by numerous virtuosic manipulations of series so as to obtain representations of solutions to differential equations. A little later, the problem of the convergence of these series will arise, which will constitute the central theme of Cauchy's work (1824), leading to a famous existence theorem, the "Cauchy-Lipschitz theorem", so called after an improvement by Lipschitz. This theorem will know various refinements and various demonstrations throughout the nineteenth century (Gilain 1994, pp. 446-447).

During this second period, which goes, in my selection, from Euler to Poincaré, we find almost no more diagrams in the theoretical treatises. The Lacroix's case, contrary to appearances, does not contradict this scheme. Indeed, Lacroix (1798) generally adopts Euler's point of view, but he also wants to give a historical dimension to his treatise, by giving many references and a statement of the old theories in counterpoint of the most recent theories. Moreover, unlike other authors, he also pushes the applications of differential equations to geometry rather far. The 11 diagrams mentioned in the table are linked either to old theories or to applications. The same applies to Boole's case (1859), a perfect representative of the English algebraic school: the four diagrams mentioned for him are related to geometric applications given as exercises. Finally we thus have a little more than a century during which no diagram is directly associated with the proper theory of differential equations. Of course, we are talking here of theoretical treatises of a fairly high level: in some applied research or other pedagogical contexts, the manners of ancient geometry may often persist, notably as a practical tool for formulating differential equations with the Leibnizian language of differentials. To give only one example, we can find such diagrams in Laplace's early work in celestial mechanics during the years 1773-1778 (Laplace 1891, pp. 202, 222, 268, 491; 1893, pp. 72, 73, 93).

A new period begins with Poincaré (1881-1886) who again pays attention to the curves defined by differential equations, but from a different perspective, that of the global qualitative study of the integral curves. Diagrams make a strong comeback in this new context. The method of series representations having reached in a sense its limits, it is in fact this surprising return to a geometric framework that will enable further progress. The previous analytical tradition still continues, of course, developing in parallel to the newly emergent qualitative current.

We are now going to look at some examples to clarify the various roles played by diagrams, either by their presence or their absence in these three periods. 


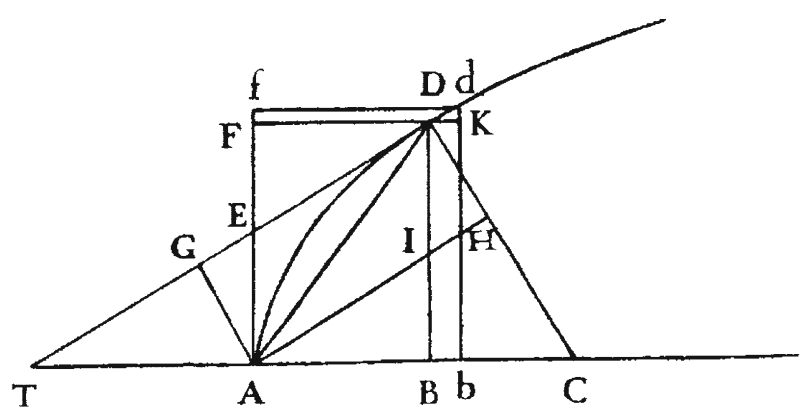

Fig. 1 Introductory diagram of Manfredi's treatise (Manfredi 1707, pl. 1)

\section{From Manfredi to Riccati}

\subsection{Manfredi's treatise}

Let us start with Gabriele Manfredi's first diagram (Fig. 1). The 1707 treatise, entitled De constructione aquationum differentialium primi gradus, describes, in an orderly manner, the many results about first order differential equations that were previously scattered throughout the mathematical literature. The book, praised by Leibniz and Johann Bernoulli, quickly gained a great reputation in all Europe. It was regarded as the equivalent in the subject of the integral calculus to L'Hospital's Analyse des infiniment petits (1696) in the subject of the differential calculus.

The first proposition formulates the famous inverse tangent problem:

Given an equation expressing a relationship between the sub-tangent BT to a curve $\mathrm{AD}$ described on the axis $\mathrm{AB}$, or the sub-normal $\mathrm{BC}$, or the tangent $\mathrm{DT}$, or the normal $\mathrm{DC}$, and the coordinates $\mathrm{AB}, \mathrm{BD}$ of the curve and some constants, or quantities depending in any manner on coordinates and constants, to find a first order differential equation to construct the curve. ${ }^{3}$

Here, the diagram is essential, in giving meaning and support to definitions and reasoning that are not fully formulated discursively. Without the diagram, the text makes no sense. In particular, there is no prior definition of a curve, nor of a tangent, nor of a subtangent, etc. Certainly, we can assume that the author refers to a culture common to its readers, but these notions of curve or tangent are not further defined in a consistent manner by other authors at the time. In fact, they are concretely defined by their diagrammatic representation. Regardless of the definitions, in other parts of the treatise, the reasoning often follows what we can see on the diagrams and would be impossible without them.

One could argue that this diagram represents a very specific curve (associated notably to an increasing and concave function), but, in fact, it has a general significance. Its

\footnotetext{
3 "Si detur æquatio exprimens relationem BT subtangentis describendæ curvæ $\mathrm{AD}$, in axe $\mathrm{AB}$, aut subnormalis BC, aut tangentis DT, aut normalis DC, ad coordinatas AB, BD, \& constantes quasvis, aut ad quantitates, quæ per coordinatas, \& constantes quomodocumque dentur; invenire æquationem differentialem primi gradus curvæ describendæ" (Manfredi 1707, p. 16).
} 
sole purpose is to highlight the similarity relations between the different triangles on which the reasoning rests: the infinitesimal triangle $\mathrm{D} k d$ on the one hand, the ordinary triangles TBD, DBC, AGE, DFE, TAE, etc., on the other. These relationships exist regardless of the curve and are only intended for use in reasoning. The purpose of this generic diagram is primarily to promote visual thinking, to create a mental image that summarizes the links between the various elements of the problem. It is both an illustration necessary to complete the discourse and a useful tool to facilitate the conduct of reasoning.

We cannot either evoke here the well-known dangers of inadequate graphical representation of continuity and differentiability (Giaquinto 1994; Mancosu 2005), related to the existence of "monsters" discovered at the end of the nineteenth century, because the only question in Manfredi's theory is to integrate differential equations by quadratures. The reference functions of this theory are those which can be expressed by a finite number of algebraic operations and quadratures (these functions will be called later "Liouvillian", when Liouville will have rigorously determined the scope and limitations of their use). The graphs of these functions are extremely smooth and regular. For them, diagrams like Manfredi's ones constitute a good mental image likely to support geometric intuition in a reliable way.

The handling of these diagrams and the development of reasoning from them constantly rest on two implicit principles:

- A principle of continuity, the same that is effective since Euclid to justify notably that curves cut themselves and that there exist points of intersection as we perceive them on diagrams (this principle is necessary as soon as two or several curves occur on the same diagram);

- A Leibnizian principle seeing curves as polygons with an infinite number of infinitely small sides, each of these sides being likened to a segment of tangent (this principle allows one to identify, in one's reasoning, the small arc $\mathrm{D} d$ of the curve with the hypotenuse of the right-angled triangle $\mathrm{D} k d$ ).

To apply this last principle, it is also necessary to accept a kind of permanence of properties during the passage from small quantities to infinitely small ones: on diagrams, infinitesimal increases of quantities are represented by finite segments, to which one applies ordinary geometric reasoning, for example by writing similarity relations between the Leibnizian characteristic triangle and a common triangle.

\subsection{Riccati's tractional motion}

Now I want to analyze more extensively the treatise published in 1752 by Vincenzo Riccati, De usu motus tractorii in constructione aquationum differentialium. ${ }^{4}$ This treatise occupies a particular place in our history because it is an accomplished work situated at the end of the first period. Its theoretical content is very rich. In it, Riccati succeeds in demonstrating that any curve defined by a differential equation can be constructed by a tractional motion. This result is the counterpart, for transcendental curves, of the one that Descartes had obtained for algebraic curves and the

\footnotetext{
${ }^{4}$ A French translation of this treatise can be found in Tournès (2009).
} 
motion of linkages. So Riccati's work can be considered as a distinctive achievement in the theory of construction of equations by simple continuous motions, a theory that flourished in the first half of the eighteenth century before suddenly disappearing.

A tractional instrument is an instrument that plots an integral curve of a differential equation by using tractional motion. On a horizontal plane, one pulls one end of a tense string, or a rigid rod, along a given curve, and the other end of the string, the free end, describes in its motion a new curve which remains constantly tangent to the string. By suitably choosing the base curve along which the end of the string is dragged, and by suitably varying the length of the string according to a given law, one can integrate various types of differential equations. In this way of solving an inverse tangent problem, one actually materializes the tangent by a tense string and one moves the string so that the given property of the tangents is verified at every moment (Tournès 2003a, 2009).

\subsubsection{Algebraic treatment of diagrams}

First of all, the study of such motions reveals some limitations of traditional diagrams. Indeed, it is difficult to represent a motion on a static figure. In Fig. 2, one can see the first four diagrams of the treatise which are used to elaborate the theory. Riccati considers a curve $\mathrm{AB}$ with coordinates $\mathrm{KG}=x$ and $\mathrm{GE}=y$; this curve is called the "base" of the tractory. Along the curve one pulls a string of length $\mathrm{EF}=a$, and this motion generates the tractory $\mathrm{CD}$. Then, having chosen a constant $b$, one constructs the point $\mathrm{M}$ so that $\mathrm{MG}=b$, and the point $\mathrm{N}$ of line $\mathrm{GE}$ so that $\mathrm{MN}$ is parallel to
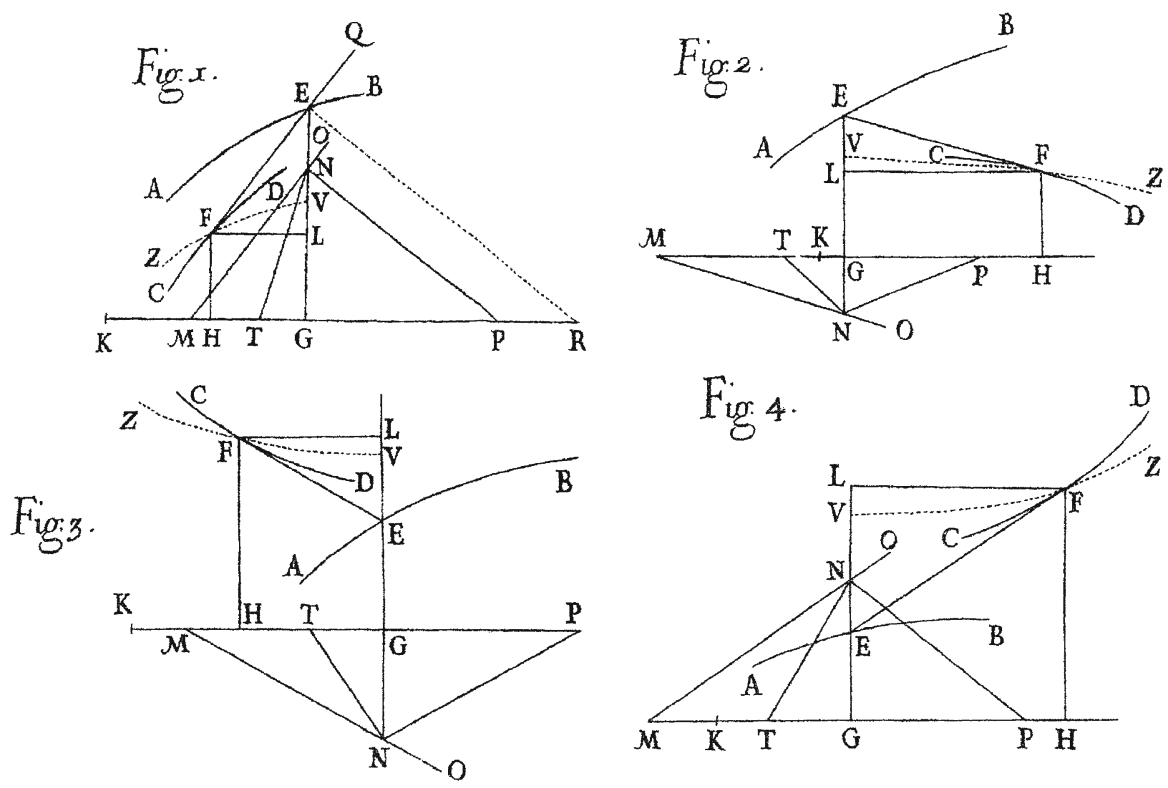

Fig. 2 The four cases of tractional motion (Riccati 1752, pl. 1) 
string FE. Finally, one puts GN $=q$, which is the quantity sought. The analysis rests on the separation of four cases, as the string is placed below or above the base and as one pulls its end to the right or to the left.

Throughout the text, the formulas contain four superposed signs related to the four possible configurations respectively. For example, the differential equation satisfied by the sought quantity $q$ is written in the following way:

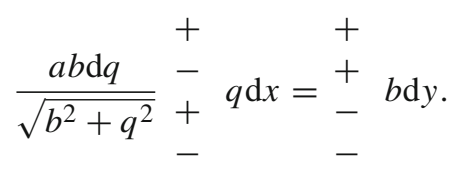

The manipulation of such formulas is, of course, inconvenient. A first complication of Cartesian geometry comes from the fact that coordinates of curves are lengths, which are positive quantities. In particular, the ordinates of a curve are treated as positive, whether this curve is located on one side or on the other one of the axis. Beyond this simple case, geometers often choose different coordinate systems for different curves drawn on the same diagram to be able to manipulate only positive coordinates. A second complication arises with the calculation of differences: practically, it is frequent that the correct sign of differential quotients cannot be determined except by looking at the diagram.

What is already complicated in a static diagram, is even more so in a dynamic diagram. When we draw a tractory, we move the string along the base. During this motion, it may happen, of course, that we pass suddenly from one case to another. How to manage concretely such a situation? Should we study the tractory by dividing it into several pieces? Should we change equations in the middle of our computation? Riccati's answer to these unpredictable evolutions is both surprising and effective. To put the problem in equation, he chooses an initial configuration so that all involved quantities take positive values. Then, no matter what happens, he stays with this case, which means that he allows the variables to change sign. So it can happen that the dependent variable becomes negative during the motion, if the point $\mathrm{N}$ goes to the other side of the axis. In the situation of Riccati's Figs. 2 and 3, it may even happen that $q$ is at first positive for the first part of the integral curve below the axis, then becomes negative for the other part of the same curve above the axis. As a matter of fact, once the problem has been formulated as an equation according to the usual interpretation of all the letters as representative of lengths, everything proceeds as if we forgot geometry and let algebraic equations live by themselves. This set of diagrams highlights well a time of transition to an oriented geometry: as a consequence of the fact that diagrammatic and algebraic representations do not fit well together, Riccati accepts implicitly the idea that letters are reliable to assign oriented lengths.

In also studying all topological configurations of a diagram and searching for a unique algebraic description, Carnot exhibits the same attitude in his Géométrie de position (1803):

Leibniz wanted one to be able to build into the expression of the conditions of a geometric problem the diversity of position of the corresponding parts of the 
related diagrams, so that by separating them with a very distinctive character, one could be able to isolate them more easily in the calculation. And this diversity of positions often expresses itself by simple mutations of signs; and it is precisely the theory of these mutations that makes the essential object of researches which I have in mind, and which I name Geometry of position. ${ }^{5}$

The way which Riccati transforms one diagram into another, while allowing some quantities to be expressed by negative numbers, brings to mind strikingly Carnot's "correlation principle", a laborious method of ascribing signs to geometrical quantities. Caparrini (2006) shows that Carnot's essay was probably a key common factor in the discovery by six mathematicians (Wessel, Buée, Argand, Mourey, Warren and Gauss) of oriented geometry and the geometric representation of complex numbers. Riccati's attempts could be considered as an interesting intermediate step between Leibniz' geometry of situation and Carnot's geometry of position. Riccati did not follow through to the end what his modeling of tractional motion could have suggested to him-namely he always leaves sign expressions in front of letters, rather than having letters represent signed quantities, which would have allowed a single algebraical description of all cases. Nevertheless, his diagram-based geometric work remains worthy of interest.

\subsubsection{Construction of curves by tractional motion}

More generally, in Riccati's memoir, we must keep in mind that the printed diagrams are only imperfect images of diagrams in motion, which should be regarded as the true diagrams. Let's examine a single example, which will be enough to understand the construction pattern of a differential equation by tractional motion. In the example the task Riccati sets for himself is the construction of an equation that is not integrable by quadratures. There is therefore no finite formula that would allow him to construct the curve by points from its coordinates. The method he employs consists in pulling a string EF, from an initial position $\mathrm{AC}$, along a well-chosen auxiliary curve $\mathrm{AB}$. The free end $\mathrm{F}$ of the string draws a new curve $\mathrm{CD}$, which is a tractory of the curve $\mathrm{AB}$. Finally, a point $\mathrm{N}$ algebraically linked to EF draws the integral curve. It is unnecessary to give here more details: it is enough to understand that we could integrate in a similar way any differential equation by adding the tractional motion to the usual algebraic operations and to the quadratures. Tractional motion thus extends the field of constructible curves.

Figure 3 has multiple functions: it serves to illustrate Riccati's reasoning, but it is also a description of the continuous motion that allows the exact description of the curve sought. This motion is suggested by the drawing of several successive positions $\mathrm{EF},{ }_{2} \mathrm{E}_{2} \mathrm{~F},{ }_{3} \mathrm{E}_{3} \mathrm{~F}$ of the pulled string. The real diagram that Riccati has in mind here is a dynamic diagram, taking into account the supplementary dimension of time. In

\footnotetext{
5 “Leibniz vouloit qu' on fît entrer dans l'expression des conditions d'un problème géométrique, la diversité de position des parties correspondantes des figures comparées, afin qu'en les séparant par un caractère bien distinctif, on pût les isoler plus facilement dans le calcul. Or cette diversité de positions s'exprime souvent par de simples mutations de signes; et c'est précisément la théorie de ces mutations qui fait l'objet essentiel des recherches que j'ai en vue, et que je nomme Géométrie de position" (Carnot 1803, p. ij).
} 
Fig. 3 A diagram evoking the motion of a string (Riccati 1752, pl. 1)

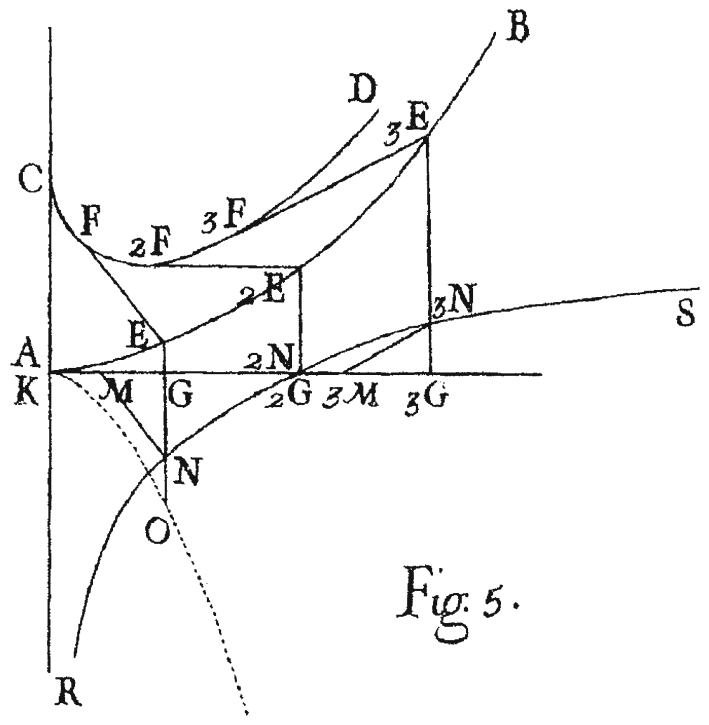

other words, the diagram is also the description of a mechanism to draw the integral curve by continuous motion.

Thus, the diagram enables one to grasp the tractional motion but, conversely, it is only this motion that allows one to construct the diagram, because the differential equation is not integrable in finite form. So we might ask how the diagrams of the treatise have been drawn. We do not know exactly, but they are too precise to be mere freehand sketches. In fact, Riccati indirectly provides information on the process used because, after studying the possibility of making mechanical instruments to realize the various tractional motions needed, he suggests for cases where one lacks these instruments an alternative construction by small segments of tangents, in accordance with the principle of the Leibnizian polygon. Riccati himself probably applied this method of approximate construction to realize the diagrams of his memoir. Figure 4 gives a possible reconstruction in this style of the curve $C D$ from the curve $A B$.

For Riccati, the diagram and the motion describing it are tools for a qualitative analysis of the differential equation. They allow the presentation of the form of the integral curves in the case in which there is no algebraic formula to represent these curves. Let us consider a significant example in the treatise. It is about an equation illustrated in Fig. 5.

On the basis of a mental visualization of the motion of the string EF pulled by its extremity $\mathrm{E}$ along the base curve $\mathrm{ALB} l$ (here a closed curve), Riccati describes the behavior of integral curves RNS:

Since the basis ALB $l$ of the tractory is a curve returning on itself, the tractory will perform an infinity of turns and will have an infinite number of tangents parallel to the axis, as well as an infinite number of tangents perpendicular to the axis. Therefore the curve will have an infinite number of asymptotes and will cut the axis in an infinite number of points. In fact, when the tangent to the tractory 
Fig. 4 Modern reconstruction of Riccati's previous diagram

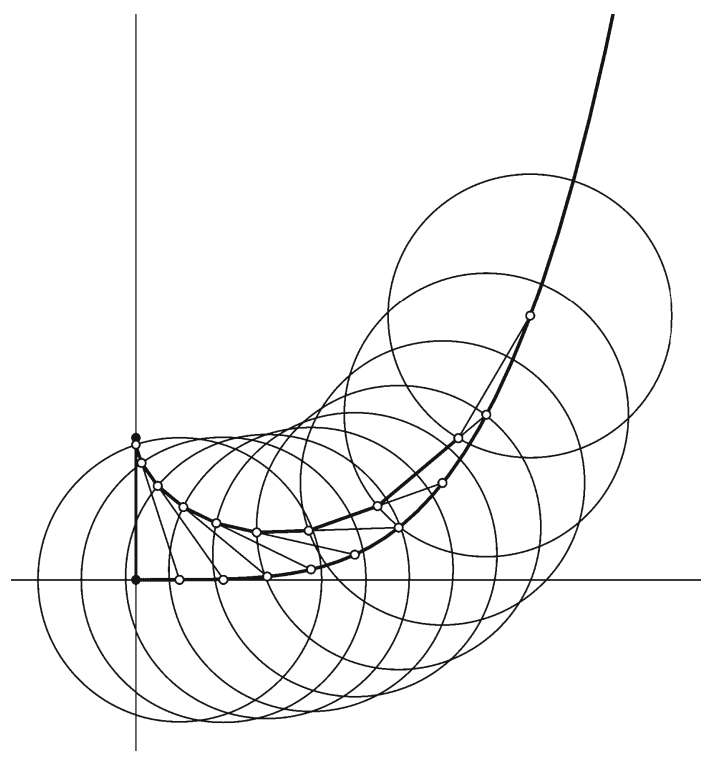

Fig. 5 A diagram allowing

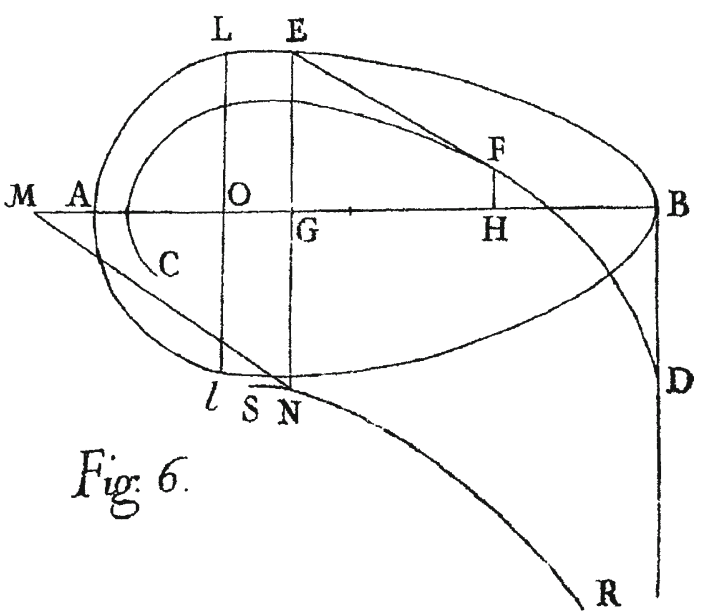
qualitative analysis (Riccati 1752, pl. 1)

is normal to the axis, this causes an asymptote to the curve generated, and when the tangent to the tractory is parallel to the axis, the generated curve has ordinate $q=0$, that is to say cuts the axis. ${ }^{6}$

\footnotetext{
6 "Quoniam basis tractoriæ $\mathrm{ALB} l$ est curva in se ipsam rediens, tractoria infinitos gyros absolvet, atque habebit infinitas tangentes parallelas axi, infinitas eidem perpendiculares. Quare curva RNS prædita erit infinitis assymptotis, \& in infinitis punctis secabit axem. Nam quum tangens tractoriæ est normalis axi, enascitur assymptoton in curva genita ; quum autem axi est parallela tractoriæ tangens, curva genita habet ordinatam $q=0$, adeoque axem secat" (Riccati 1752, p. 12).
} 


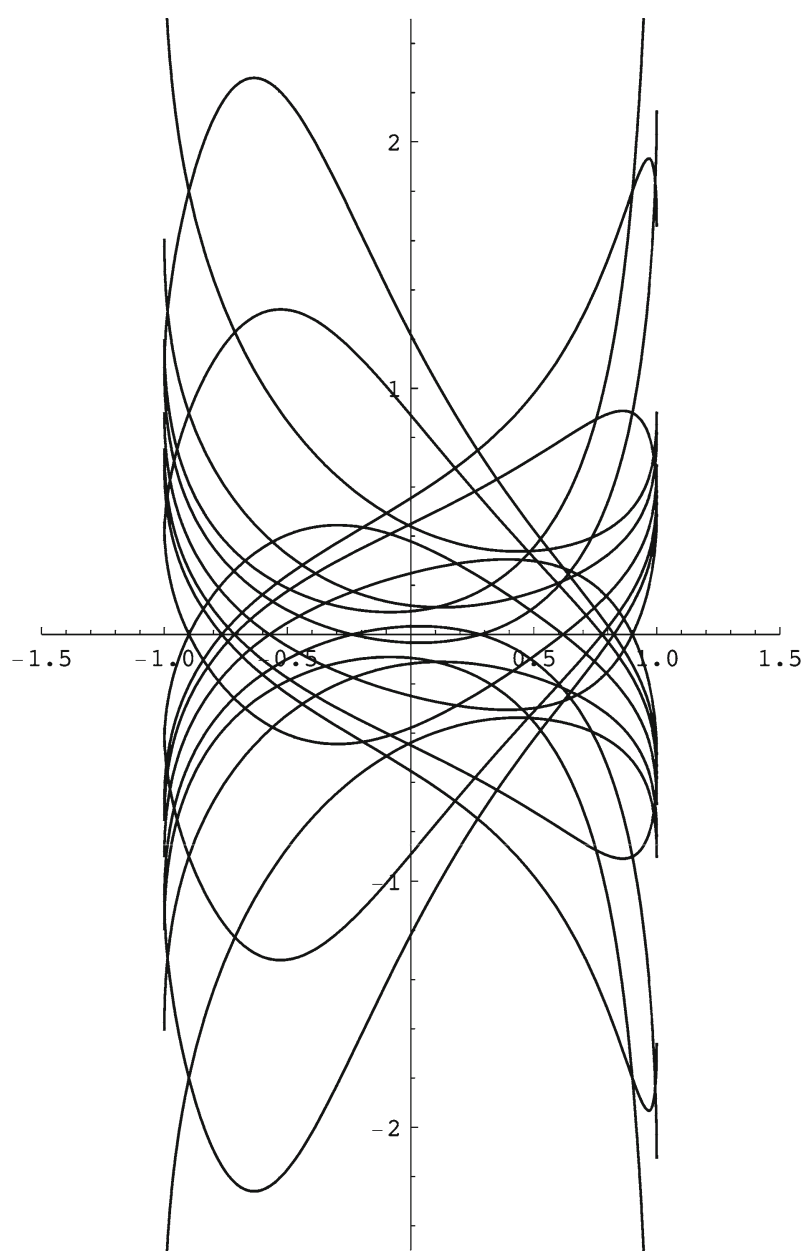

Fig. 6 Modern reconstruction of integral curves associated to Riccati’s previous diagram

A plot with modern computing software provides the following diagram (Fig. 6) which confirms Riccati's assertions. Here, in fact, as the string successively takes the four basic positions reviewed above, tractional motion integrates at the same time the four differential equations corresponding to the four possible combinations of signs for the coefficients of the original equation. For this reason, we can observe four bundles of integral curves on Fig. 6.

So, in the absence of any analytical expression of the solutions of the differential equation, Riccati's method of tractories allows to construct the integral curves and to study their global behavior, contrary to the method of series which would only allow a local study. As the previous example illustrates, a rough diagram achieved on paper to represent the beginning of the motion and mental visualization of the continuation of the motion is certainly a way to discover some non-obvious properties of integral curves, such as the existence of asymptotes. Such a practice of visual and kinesthetic 
representation seems here adequate to create knowledge and to develop new forms of intuition.

These diagrams raise important questions. Can we conceive a curve independently of the motion that is used to describe it? And how to realize this motion without using an instrument? The importance of the generation of curves by motion in the seventeenth and eighteenth centuries is obvious when we see the numerous treatises of "organic geometry" written by excellent mathematicians: Cavalieri, L'Hospital, Newton, Van Schooten, and so on. In fact, by Riccati's way of thinking, a differential equation is more than a curve. It is the description of a motion that generates a curve. And it is at the same time the description of an exact continuous motion and that of a discrete approximate motion. For Riccati, a diagram is thus an algorithm of construction inscribed in the time. This conception reminds me of some considerations advanced recently by Giuseppe Longo:

I believe that today we can consider geometry, thanks to breakthroughs of biologists and physiologists, as a science of the action and the anticipation of the motion in space: the segment, the curve, the circle are not the 'abstract form' of a material object, nor 'ideal diagrams', but the anticipation of a journey. And the prediction is already an abstraction; the trajectory planned or anticipated by glance and gesture is abstract. ${ }^{7}$

This applies particularly well to differential equations, because the image of a moving point drawing a curve is naturally associated with the foundations of calculus. This vision of a differential equation as a description of a motion drawing a curve will be shared by the engineers and manufacturers of instruments who, in the late nineteenth century and the first half of the twentieth, will make concrete tractional instruments (Tournès 2009). I would like to quote in particular Vannevar Bush, who built large differential analyzers in the 1930s to solve the complex differential equations needed to model the new electricity and telephone networks:

This is actually one of the most attractive aspects of the machine; one acquires an entirely new appreciation of the innate nature of a differential equation as that experience is gained. (Bush 1931, p. 451)

\section{From Euler to Cauchy and Lipschitz}

After 1750, as we said, diagrams disappeared almost completely from treatises on differential equations. Up until then, to solve an algebraic or differential equation was primarily to construct its solution by the intersection of drawn curves. Such a construction, if it could be carried out by simple continuous motions, played the role of an existence proof in analysis. In this sense, tractional motion contributed significantly

\footnotetext{
7 “Je crois qu'aujourd'hui on peut considérer la géométrie, grâce aux percées des biologistes et des physiologistes, comme une science de l'action et de la prévision du mouvement dans l'espace: le segment, la courbe, le cercle ne sont pas la 'forme abstraite' d'un objet matériel, ni des 'figures idéales', mais plutôt la prévision d'un parcours. Et la prévision est déjà une abstraction; la trajectoire prévue ou anticipée par le regard et le geste est abstraite" (Longo 1997, p. 217).
} 
to the legitimation of transcendental curves. But gradually, the predominance of this geometric way of thinking faded away, replaced by an innovative and autonomous algebraic way of thinking.

Euler sets the tone: his Institutiones calculi integralis of 1768 and 1769 are purely algebraic. To solve a differential equation is no longer to construct a curve, it is now to express its solution in the form of an algebraic formula, most often infinite. Euler's treatise thus consists mostly in extremely elaborate manipulations of infinite series. To solve a differential equation has become essentially to transform it into a new equation in which there are no longer infinitely small quantities, even if this new equation has a complex form, which overflows in the margins of the book and is difficult to manage in applications.

Let us note however that, although there is no diagram and the vocabulary is almost exclusively algebraic, we find some traces of geometrical terms that have survived. Though there are shifts of meaning with these terms, they always evoke the former constructions: Chapter X of the second volume is indeed entitled "De constructione æquationum differentio-differentialium per quadraturas curvarum”. Also note that in his applied research, including ballistics and celestial mechanics, Euler adopts a less extreme position and allows himself the use of diagrams, mostly those by methods of approximation, for heuristics, illustration or application. In three memoirs, he even employs the tractional motion in the same spirit as Vincenzo Riccati. Of course, it would be interesting to study in more detail this duality in Euler's attitude arising from the separate contexts of his theoretical and applied works.

\subsection{Lacroix’ pragmatic compromise}

The second volume of the Lacroix' Traité du calcul différentiel et du calcul intégral, published in 1798 , is particularly interesting to study because it lies at the crossroads of old and new conceptions. While adopting Euler's point of view, Lacroix cannot totally abandon the former geometrical conceptions, although he considers them old-fashioned. All the traditional geometric vocabulary related to the inverse tangent problem is described as outdated: for Lacroix, the old geometric constructions are less convenient than the approximate formulas that have taken their place. By "approximate formulas", he means series and other infinite algorithms now used to represent the solutions of differential equations.

Although geometrical methods are displayed as old-fashioned, Lacroix does not hesitate to use them to prove the existence of a solution of a differential equation satisfying a given initial condition. Having first provided evidence for a solution by manipulating series, he writes:

The preceding shows that the first order differential equations in two variables are always possible, that is, that one can always assign values either exact or approximate to the function that they determine; the same thing is also proved by geometrical considerations. ${ }^{8}$

\footnotetext{
8 "Ce qui précède fait voir que les équations différentielles du premier ordre à deux variables sont touj-
} ours possibles, c'est-à-dire, qu'on peut toujours assigner des valeurs soit rigoureuses, soit approchées de la 
Fig. 7 Illustration of the polygonal method (Lacroix 1798, pl. 2)

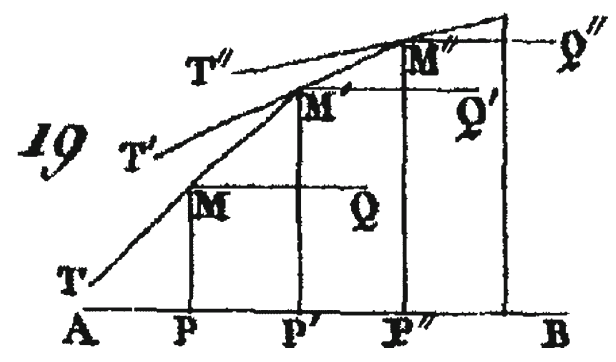

He then describes the construction of a polygon formed by small tangent segments, the slopes of which are provided by the differential equation (Fig. 7), and concludes:

We can see that by continuing this process, we will draw a polygon that will differ from the curve to which belongs the proposed equation, as we multiply the sides. It also follows from this construction that a first order differential equation represents an infinite number of curves, since we can take the first point $\mathrm{M}$ anywhere we wish. ${ }^{9}$

The Leibnizian conception is still pregnant. Lacroix needs this diagram to be convinced of the existence of solutions of differential equations. His presentation, unchanged since Leibniz, is at the source of the existence proof that Cauchy will give in 1824, by formalizing more rigorously the underlying passage to the limit.

\subsection{Moigno’s virtual diagrams}

In Cauchy's lessons at the École Polytechnique in 1824, Published in Cauchy (1981), there is no diagram and no reference to a curve and its tangents. But in Moigno's treatise, written in accordance with Cauchy's approach, there is roughly the same geometrical proof as in Lacroix, as if Moigno was not totally convinced by Cauchy's abstract algebraic speculations. At first, Moigno gives a definition expressed in terms of functions:

To integrate differential equations is to find the functions they determine, or at least new equations which contain the variable and the functions in question. These equations are called integral. ${ }^{10}$

\footnotetext{
Footnote 8 continued

fonction qu'elles déterminent : la même chose se prouve aussi par des considérations géométriques" (Lacroix 1798 , p. 287).

9 “On voit, qu'en continuant ce procédé, on tracera un polygone qui différera d'autant moins de la courbe à laquelle appartient l'équation proposée, qu'on en multipliera les côtés. Il résulte aussi de cette construction qu'une équation différentielle du premier ordre représente une infinité de courbes, puisqu'on peut prendre le premier point M où on voudra" (Lacroix 1798, p. 287).

10 “Intégrer des équations différentielles, c'est trouver les fonctions qu'elles déterminent, ou du moins des équations nouvelles qui ne renferment que la variable et les fonctions dont il s'agit. Ces équations nouvelles se nomment integrales" (Moigno 1844, pp. 333-334).
} 
However, just after he returns to the ancient point of view of the construction of curves:

To integrate is to construct the curve or at least to determine it by its equation. We will prove later analytically and rigorously that the integral of any first order equation in two variables exists, and that we can also obtain approximate values of it as precise as we want; some geometrical considerations also put this existence beyond all doubt. ${ }^{11}$

After that, he replicates almost literally Lacroix's reasoning, but without a diagram. Points are defined by their coordinates, tangents by a point and a slope. We have here a kind of virtual diagram that one must have in mind, but that is no longer physically drawn on the paper, or at least which is left to the reader to draw. At the end, Moigno concludes exactly like Lacroix. What the presentation of the proof suggests is the idea that without the presence of the diagram in the background, it would be very difficult to understand Cauchy's abstract presentation. This situation is frequent in the analytical period after 1750: mathematicians commonly evoke geometrical diagrams with words rather than drawing them. For example, in his textbook Leçons sur le calcul des fonctions (1806, p. 268), Lagrange proves that a singular integral of a differential equation corresponds to the envelope of curves defined by the complete integral of the equation, and he describes this complex situation with a relatively long textual development when a diagram would have been more efficient. The diagram plays here an important role by its absence. We are somewhat in the same situation as when, in the 1960s, Jean Dieudonné published a book of elementary geometry without diagrams (Dieudonné 1964). Such a book is understandable only if the reader draws himself the diagrams or if he has already met them before and keeps them in mind.

\section{The return of the curves defined by differential equations}

\subsection{Poincaré's qualitative theory}

With Henri Poincaré, we discover a new change of perspective. ${ }^{12}$ Beginning in 1881 , Poincaré publishes in several installments a great memoir on the curves defined by a differential equation (Poincaré 1881-1886). Its title is already a whole program. The series method, which had been use immoderately for over a century, was then meeting several difficulties. There were series that converged too slowly to be employed in numerical calculation, as well series (notably in celestial mechanics) that did not converge at all. More generally, theoretical complications in studying the properties of a function defined by a series were being encountered. In what might appear at

\footnotetext{
11 “Intégrer c' est construire la courbe ou la déterminer au moins par son équation. Nous prouverons plus tard analytiquement et rigoureusement que l'intégrale d'une équation quelconque du premier ordre à deux variables existe, et qu'on peut en obtenir des valeurs aussi approchées que l'on voudra; quelques considérations géométriques mettent aussi cette existence hors de doute" (Moigno 1844, p. 335).

12 Historians have extensively studied the genesis and development of Poincaré's qualitative theory. Among the important papers on the topic are Gilain (1991), Chabert and Dahan Dalmedico (1992), Kolmogorov and Yushkevich (1998, pp. 173-196), Bottazzini (2000, pp. 56-63). Nevertheless, these studies pay little attention to the role of diagrams as such.
} 
first glance like a backward step, Poincaré focuses again on the geometric aspect of a differential equation, namely the curves it defines:

A complete theory of the functions defined by differential equations would be of great utility in a large number of questions of pure mathematics and mechanics. Unfortunately, it is clear that in the large majority of the cases that appear we cannot integrate these equations by means of functions already known, for example by means of functions defined by quadratures. [...]

It is therefore necessary to study the functions defined by differential equations in themselves and without trying to bring them back to simpler functions. [...] We have already made a first step in this way by studying the given function in the neighborhood of one point in the plane. It is now time to go further and study this function throughout the entire plane. [...]

It is naturally by the qualitative part that we must begin the theory of any function and that is why the problem, which first occurs, is the following one:

To construct the curves defined by differential equations. ${ }^{13}$

In this problematic of direct construction of curves from the differential equations without attempting to determine the functions that these curves represent, it seems that we are very close to what we saw in the eighteenth century with Vincenzo Riccati. However, Poincaré's position is very different: he is by no means interested in the precise drawing of a single integral curve, but in the global aspect of the set of all integral curves.

To implement his program, Poincaré considers first of all the first order differential equation

$$
\frac{\mathrm{d} x}{\mathrm{X}(x, y)}=\frac{\mathrm{d} y}{\mathrm{Y}(x, y)}
$$

where $\mathrm{X}$ and $\mathrm{Y}$ are real polynomials in $x$ and $y$, and is interested in the integral curves defined by this equation, which he calls "characteristics". We know from Cauchy's work that one integral curve and only one passes through any point in the plane, aside from the points - called "singular points"-located at the intersection of the curves of the equations $\mathrm{X}=0$ and $\mathrm{Y}=0$. Poincaré begins therefore by undertaking a classification of singular points and a description of the behavior of integral curves near these points. For this study, he uses a gnomonic projection of the plane on a sphere, which

\footnotetext{
13 "Une théorie complète des fonctions définies par les équations différentielles serait d'une grande utilité dans un grand nombre de questions de Mathématiques pures ou de Mécanique. Malheureusement, il est évident que dans la grande généralité des cas qui se présentent on ne peut intégrer ces équations à l'aide des fonctions déjà connues, par exemple à l'aide des fonctions définies par les quadratures. [...]

Il est donc nécessaire d'étudier les fonctions définies par des équations différentielles en elles-mêmes et sans chercher à les ramener à des fonctions plus simples. [...]

On a déjà fait un premier pas dans cette voie en étudiant la fonction proposée dans le voisinage d'un des points du plan. Il s'agit aujourd'hui d'aller plus loin et d'étudier cette fonction dans toute l'étendue du plan. [...]

C'est naturellement par la partie qualitative qu'on doit aborder la théorie de toute fonction et c'est pourquoi le problème qui se présente en premier lieu est le suivant:

Construire les courbes définies par des équations différentielles" (Poincaré 1881, pp. 375-376).
} 
does not change any global aspect of the integral curves, allows one to see them in their entirety on a bounded domain, and avoids the difficulties associated with infinite branches.

Poincaré then identifies four main types of singular points:

- "saddles", through which only two integral curves pass;

- "nodes", through which an infinite number of integral curves pass;

- "focuses", around which integral curves turn by getting closer to them like a logarithmic spiral;

- "centers", around which integral curves are closed cycles, enveloping one another.

He then shows that there are always singular points on the sphere, that we can assume without loss of generality that there are no centers, and that the numbers $\mathrm{N}$ of nodes, $\mathrm{F}$ of focuses and $\mathrm{S}$ of saddles satisfy the remarkable relation $\mathrm{N}+\mathrm{F}=\mathrm{S}+2$, similar to Euler's formula for convex polyhedra.

Having clarified behavior of singular points, Poincaré studies the relative positions of integral curves. For this, he introduces the concept of "arc without contact", that is to say, a curve which is never tangent to an integral curve. An arc without contact which closes on itself is a cycle without contact, and an integral curve crossing it cannot cross it a second time. Poincaré then shows that any integral curve which does not arrive at a node is a cycle or a spiral. In addition, a spiral rolls around a cycle, called "limit cycle". Finally, if we imagine the motion of a point along an integral curve, there are four possibilities: either we reach a node, or we run indefinitely around a focus, or we return to the starting point and we are on a limit cycle, or we turn around a limit cycle approaching asymptotically to it.

Poincaré thus created a system of geometric elements (singular points, limit cycles and cycles without contact) which, once determined by analysis, "allows one to discuss fully the forms affected by the curves defined by the given differential equation". ${ }^{14}$ As an application of this new theory, he then studies five examples that illustrate different possible situations and he draws five diagrams (Fig. 8).

It should be noticed that if this qualitative study provides the global aspect of the bundle of integral curves and their behavior in the neighborhood of the singular points, it gives no specific information on the local behavior of these curves in the neighborhood of the ordinary points. Thus, in the first example, Poincaré identifies only two nodes situated on the equator (that is at infinity in the plane) through which all the integral curves pass. His diagram is very simple. It does not display the local irregularities that exist outside the nodes (see Fig. 9 for a more precise version of this diagram in the central part of the sphere).

With Poincaré, a new type of diagrams thus appears to represent a differential equation, which differs in two ways from eighteenth century diagrams. First of all, the diagram is no longer the construction of a particular integral curve, but it tries to give an image of the bundle of all integral curves of the differential equation. Moreover, the problem is no longer to construct curves exactly with an instrument, or by points with the best possible approximation. The goal now is to draw curves freehand, respecting

\footnotetext{
14 "Permet de discuter complètement les formes affectées par les courbes que définit l'équation différentielle donnée" (Poincaré 1882, p. 274).
} 

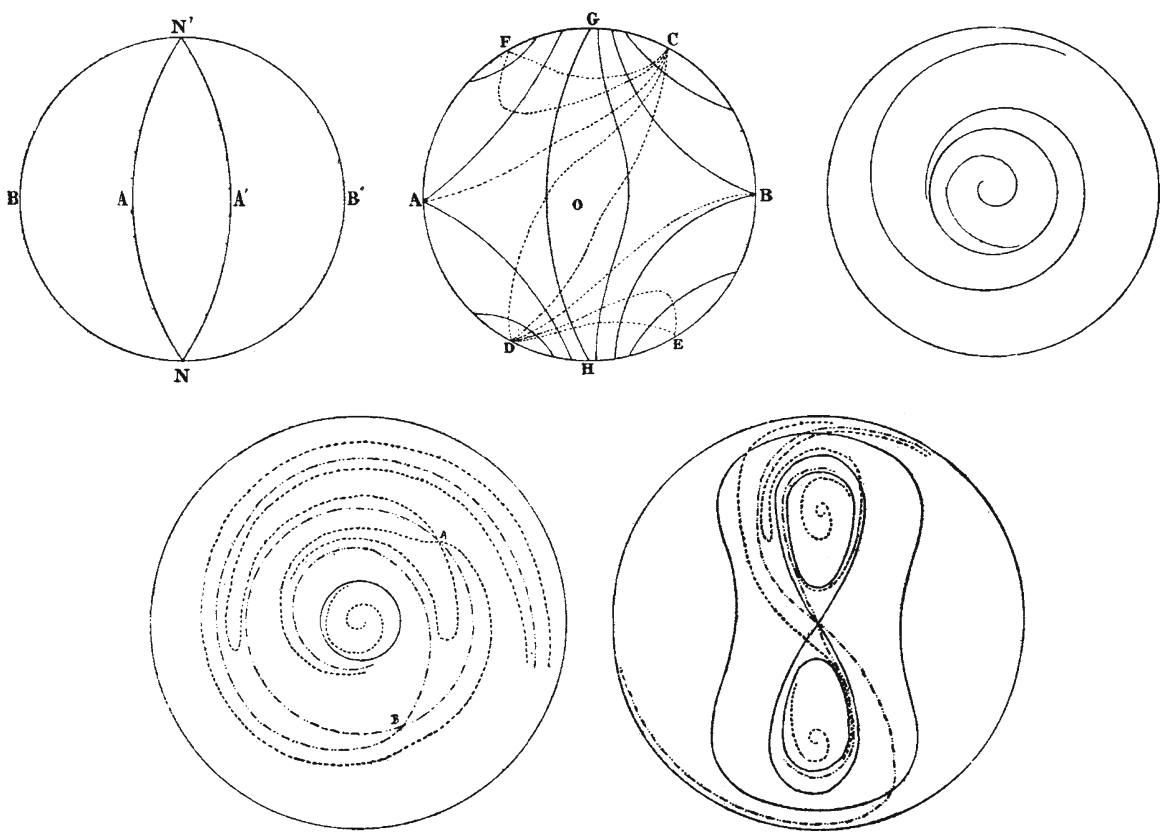

Fig. 8 Global aspect of five differential equations (Poincaré 1882, pp. 275-282)

Fig. 9 A more precise version of Poincaré's first diagram

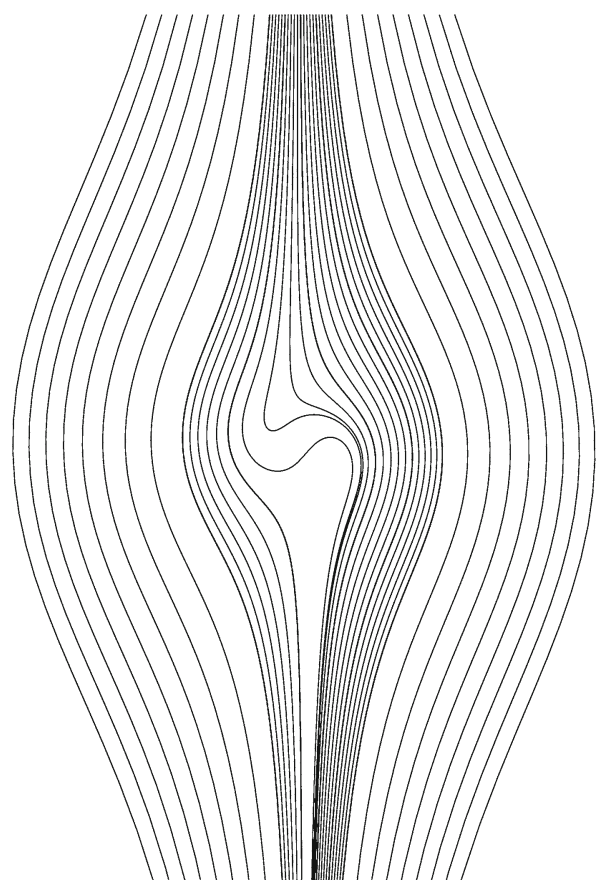


only the relative positions between the curves so that the singular points, limit cycles and cycles without contact are represented. We could say that Poincaré's diagrams are topological diagrams defined up to a diffeomorphism.

Let us now examine more thoroughly the role of these diagrams in Poincaré's thinking. The classical analytical approach of differential equations, which had developed in the second half of the eighteenth century and throughout the nineteenth century, had favored series expansions and had gradually turned towards a quasi-exclusive study in the complex domain.

As solutions could no longer be associated with real curves, this trend became in fact a permanent obstacle to geometric vision and to intuition (Israel and Menghini 1998, pp. 386-387). Analysis was in a way separated from geometry. By coming back to the real domain and looking again at the global appearance of integral curves, Poincaré does not give up analytical methods, but he wants to place them within a new geometric framework that fosters intuition. The new geometric objects that he creates from nothing (singular points, cycles without contact, limit cycles, etc.) are initially obtained by algebraic calculation, but they then allow one to construct diagrams and predict mentally the general shape of integral curves to be plotted on these diagrams. To help imagination and contribute to the appropriation of new mental objects, Poincaré regularly uses an analogy with topographical maps and vocabulary associated to them (contour lines, lines of slope, summits, valleys, passes, etc.). Although it is partly misleading (Bottazzini 2000, pp. 59-60), this reference to sensible objects known otherwise is also likely to reinforce our intuition.

Each of the diagrams that Poincare draws, to provide in a sense a "portrait" of a given differential equation, appears as an intermediate synthesis: on the one hand, it brings together in a compact outline all the results of the preliminary qualitative analysis, which would otherwise be impossible to perceive simultaneously in discursive form; on the other hand, it plays a heuristic role in stimulating further research. With the diagram, the mathematician will be able to detect significant global properties not yet proven to hold and will have a guide for local quantitative analysis of some relevant areas. As noted above, on such a diagram, the course of a particular integral curve is not necessarily accurate, but the relative positions of different integral curves can be observed. According to Poincaré, it is the only condition to be respected so that diagrams can act as efficient support in reasoning:

[...] diagrams first compensate for the infirmity of our mind by calling our senses to its aid; but it is not only that. It has often been repeated that Geometry is the art of reasoning correctly on poorly made diagrams; still these diagrams, so as not to deceive us, must respect certain conditions; proportions can be roughly corrupted, but the relative positions of the different parts should not be altered. ${ }^{15}$

\footnotetext{
15 “[...] les figures suppléent d'abord à l'infirmité de notre esprit en appelant nos sens à son secours; mais ce n'est pas seulement cela. On a bien souvent répété que la Géométrie est l'art de bien raisonner sur des figures mal faites; encore ces figures, pour ne pas nous tromper, doivent-elles satisfaire à certaines conditions; les proportions peuvent être grossièrement altérées, mais les positions relatives des diverses parties ne doivent pas être bouleversées" (Poincaré 1895, p. 2).
} 
Fig. 19 .

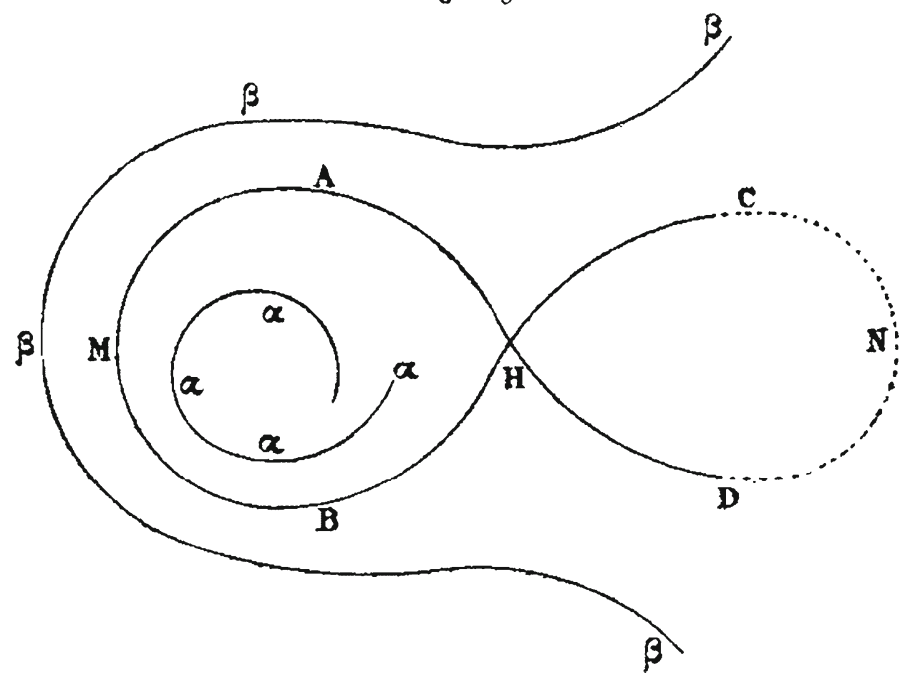

Fig. 10 A diagram supporting the reasoning (Poincaré 1882, p. 265)

Later, Poincaré will still create other geometric objects and other mental representations to extend his qualitative theory to surfaces other than the plane and the sphere, and to differential equations in greater dimensions. These reflections of a topological nature had led Poincaré to develop a new type of geometry, called "Analysis situs".

Besides the "portraits" of particular differential equations, one can discern a second type of diagram in Poincaré's memoir, those that serve as visual aids in writing demonstrations. Of course, Poincaré's style is very different from the Eulerian style. The text often rests on diagrams which are essential to present and support the arguments. There are very few calculations, very few formulas. Poincaré writes in a concise way, sometimes with a certain lack of rigor-i.e. he sometimes does not make the effort to clarify details that one can see easily on the diagram. Here, diagrams constantly guide the progress of the discursive reasoning and, as in Euclidean proofs, they are used in an essential way to infer regional or topological information. Consider, for example, the beginning of the text that comes along with Poincaré's Fig. 19 (our Fig. 10):

Let us see what happens when $\mathrm{C}$ will pass through a saddle.

Given the saddle $\mathrm{H}$, and $\mathrm{HA}, \mathrm{HB}, \mathrm{HC}$, HD the four branches of characteristics issued from this saddle, suppose that two of these branches, for example HA and $\mathrm{HB}$, arrive in a same point $\mathrm{M}$, so as to form a cycle $\mathrm{HAMBH}$; this cycle will always be a limit cycle of curves like $\alpha \alpha$; the inspection of the diagram proves it (Fig. 19). ${ }^{16}$

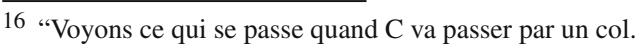

Soient $\mathrm{H}$ le col, HA, HB, HC, HD les quatre branches de caractéristiques issues de ce col. Supposons que deux de ces branches, HA et HB, par exemple, aillent aboutir à un même point $\mathrm{M}$, de façon à former un cycle HAMBH; ce cycle sera toujours cycle limite de courbes telles que $\alpha \alpha$; l'inspection de la figure le démontre (Fig. 19)" (Poincaré 1882, p. 264). 


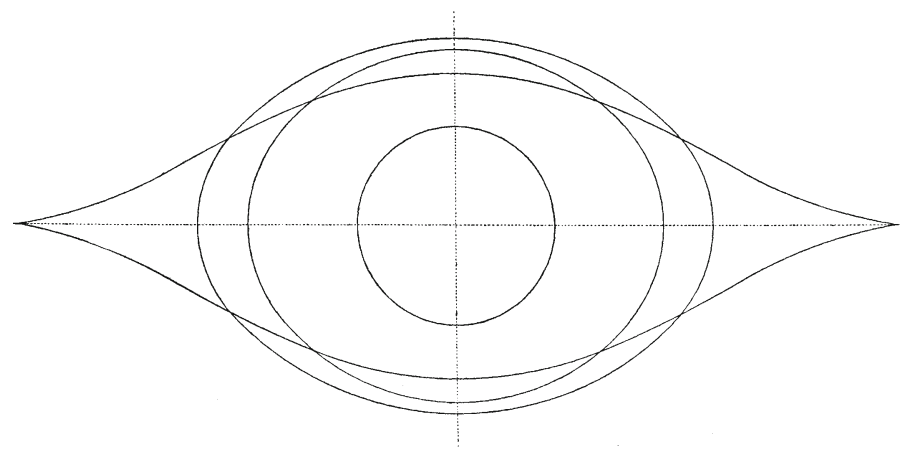

Fig. 11 Moon of maximum lunation (Hill 1878, pl. III)

Here, the diagram can achieve on the paper the mathematician's prior mental image, the one that is provided to him by intuition. Once realized, the diagram allows one to write a very short demonstration quickly, without tedious and extensive textual developments that would slow down the thought. In these conditions, the conviction comes more from the coherence of the geometric vision than from a complete logical sequence. What we see on the diagram serves as a partial proof within a piece of reasoning that remains largely implicit. ${ }^{17}$

\subsection{Analytic investigation versus geometric intuition}

One of Poincaré's main objectives in his qualitative study of differential equations was to be able to approach in an entirely new way certain classical problems of celestial mechanics, particularly the three-body problem (Barrow-Green 1997). We shall content ourselves by examining here an example which illustrates well the difference between Poincaré's geometric approach and the analytic approach of his predecessors.

In 1878, the American astronomer George William Hill published an important paper on the lunar theory, in which he could improve in a significant way the solution of the restricted three-body problem. More precisely, he found a class of periodic orbits corresponding to various possible values of the lunation (the lunation is the period between two successive new moons). For short revolution periods, he uses the series method, with several extremely technical variants. For longer revolution periods, the series method is no longer suitable and he must fall back on mechanical quadratures. He then adopts Euler's polygonal method with a sixth order Taylor expansion on each small interval. At the expense of very long and hard calculations, he achieves numerical tables for ten periodic orbits. To visualize the results, he constructs four of these orbits by points (Fig. 11): at the beginning the orbit is a circle, then it looks like

\footnotetext{
17 In line with the tradition Poincare established and in opposition to the ultra-formal bourbakist norms which came to dominate in the second half of the twentieth century, Vladimir Arnold notably employed this intuitive style of writing in his remarkable book Équations différentielles ordinaires (1974), which contains 272 diagrams. Arnold writes in the preface: "The author has attached everywhere to highlight the geometric and qualitative aspect of phenomena discussed. This book is then scattered with numerous diagrams and do not contain any formula ever so slightly tedious".
} 


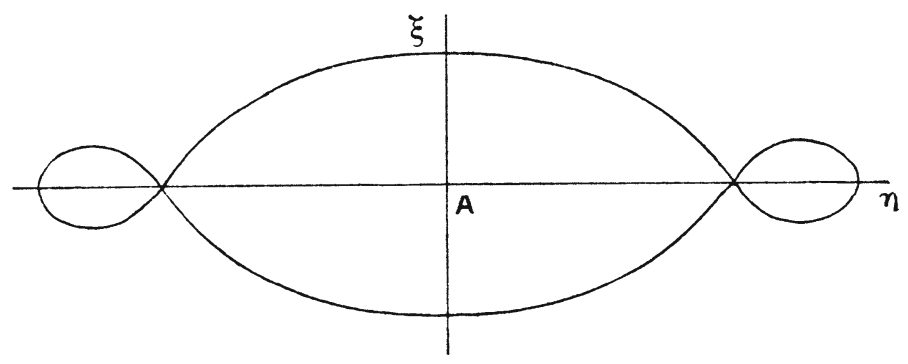

Fig. 12 Beyond the moon of maximum lunation (Poincaré 1892, p. 109)

a more and more eccentric ellipse, and finally its shape departs from that of an ellipse up to the appearance of two sharp cusps. This limit case, corresponding to the longest revolution period, is called "Moon of maximum lunation".

Hill wonders of course if we could find periodic orbits beyond this moon of maximum lunation. He makes the following conjecture:

But it is at least certain that the orbits, if they do exist, do not intersect the line of quadratures, and that the moons describing them would make oscillations to and fro, never departing as much as $90^{\circ}$ from the point of conjunction or opposition. (Hill 1878, p. 334)

In the first volume of Méthodes nouvelles de la mécanique céleste, published in 1892, Poincaré shows that Hill was wrong. By a rather simple argument of analytical continuity, he establishes that there exist, beyond the moon of maximum lunation, satellites which can be six times in quadrature (Fig. 12).

Diagrams drawn by Hill and Poincaré, although quite similar in appearance, are not of the same type and do not have the same function. Hill's diagram comes after an analytical investigation, brilliant and highly technical, but "blind"; the geometric representation is then necessary to understand numerical results that would otherwise be difficult to interpret. Once completed, it serves to support Hill's intuition (in the present case, his intuition deceives him, but that does not change anything for my analysis). In Poincaré, geometric intuition rather acts even before the diagram is drawn. Visualization takes place directly in his mind and is concretized only at the end by a diagram freehand drawn on the paper, without any numerical computation. In Hill's case, the diagram reflects precise quantitative relations and plays a heuristic role. In Poincaré's case, the diagram is purely qualitative and is used to make a prior mental image sensible. Both approaches are naturally complementary: without Hill's prior investigations, Poincaré's geometric intuition could probably not have been exercised.

The best proof that Poincaré's diagrams are primarily mental is at the end of the third volume of Méthodes nouvelles de la mécanique céleste, published in 1899. The last chapter of this volume is devoted to doubly asymptotic solutions of the threebody problem. A non-periodic solution which tends to the same periodic solution when time tends to plus or minus infinity is called "homoclinic solution". ${ }^{18}$ In an

18 On Poincaré's discovery of homoclinic solutions, see Andersson (1994). 
often-quoted passage, Poincaré describes the behavior of these solutions by evoking a virtual diagram:

When one tries to imagine the figure formed by these two curves and their infinitely many intersections each corresponding to a doubly asymptotic solution, these intersections form a kind of lattice, web or network with infinitely tight loops; neither of the two curves must ever intersect itself, but it must bend in such a complex fashion that it intersects all the loops of the network infinitely many times.

One is struck by the complexity of this figure, which I am not even attempting to draw. ${ }^{19}$

\subsection{Two precursors among the engineers}

It should be noticed that the classification of singular points obtained by Poincare had occurred earlier in the works of at least two engineers who dealt with hydraulic problems. As early as 1924, Russian historians reported a similar classification in a memoir of Nikolai Egorovich Zhukovsky dated 1876 on the kinematics of liquids. Dobrovolsky published a reproduction of Zhukovsky's diagrams (Fig. 13) in 1972 in the Revue d'histoire des sciences. In what Zhukovsky called "critical points", we recognize the saddles (1), nodes $(2,3,4)$, focuses (5) and centers (6).

The second engineer is the Belgian Junius Massau. Considered as the creator of graphical integration, he developed elaborate techniques to construct precisely the integral curves of differential equations (Tournès 2003b). Beginning in 1878, he published a large memoir on graphical integration (Massau 1878-1887, 1889), with the following objectives:

The purpose of this memoir is to present a general method designed to replace all the calculations of the engineer by graphic operations. [...] In what follows, we will always represent functions by curves; when we say 'to give or to find a function', it will mean giving or finding graphically the curve that represents it. $^{20}$

Book VI, the last book of the memoir, is devoted to applications in hydraulics. Massau examines the motion of liquids in pipes and canals. Among these specialized developments, a general and theoretical statement on graphic integration of first order

\footnotetext{
19 “Que l'on cherche à se représenter la figure formée par ces deux courbes et leurs intersections en nombre infini dont chacune correspond à une solution doublement asymptotique, ces intersections forment une sorte de treillis, de tissu, de réseau à mailles infiniment serrées; chacune des deux courbes ne doit jamais se recouper elle-même, mais elle doit se replier sur elle-même d'une manière très complexe pour venir recouper une infinité de fois toutes les mailles du réseau.

On sera frappé par la complexité de cette figure, que je ne cherche même pas à tracer" (Poincaré 1899, p. 389). Here, I have used the English translation given by Andersson (1994, p. 146).

20 “L'objet de ce mémoire est d'exposer une méthode générale ayant pour but de remplacer les calculs de l'ingénieur par des opérations graphiques. [...] Dans ce qui va suivre, nous représenterons toujours les fonctions par des courbes; quand nous dirons donner ou trouver une fonction, cela voudra dire donner ou trouver graphiquement la courbe qui la représente" (Massau 1878-1887, Livre I, pp. 13-16).
} 


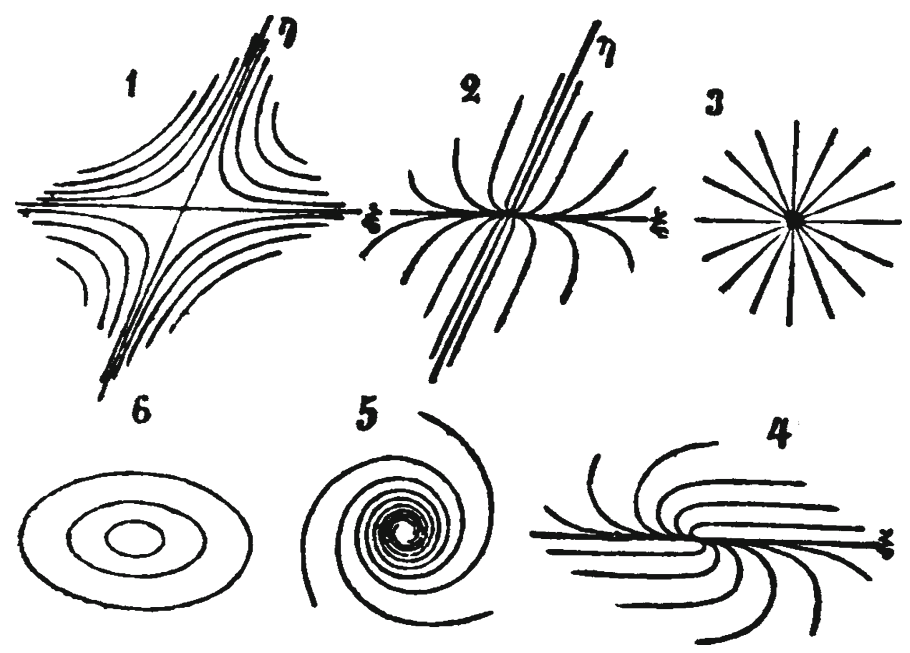

Fig. 13 Classification of singular points by Zhukovsky (Dobrovolski 1972, p. 9)

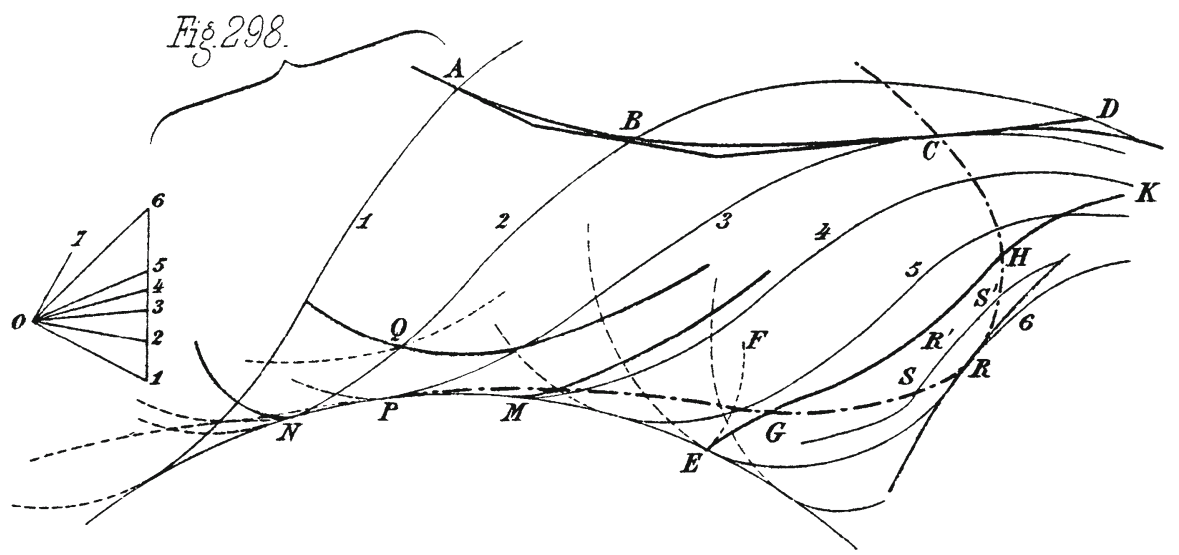

Fig. 14 Isoclines and integral curves of a differential equation (Massau 1878-1887, Livre VI, pl. 4)

differential equations appears. The entire study of a differential equation rests on the preliminary construction of the loci of points where integral curves have the same slope. Massau calls such a locus an "isocline". The isoclines (under the Latin name of "directrices") had already been introduced by Bernoulli (1694), in the beginnings of calculus, as a universal method of construction of differential equations, particularly useful in the numerous cases in which the equations cannot be integrated by quadratures.

Once enough isoclines are carefully drawn (1, 2, 3, 4, 5, 6 on Fig. 14), one takes an arbitrary point $\mathrm{A}$ on the first curve and one constructs a polygon of integration $\mathrm{ABCD}$, the successive sides of which have the slopes associated with isoclines and the successive summits of which are taken in the middle of the intervals between isoclines. 


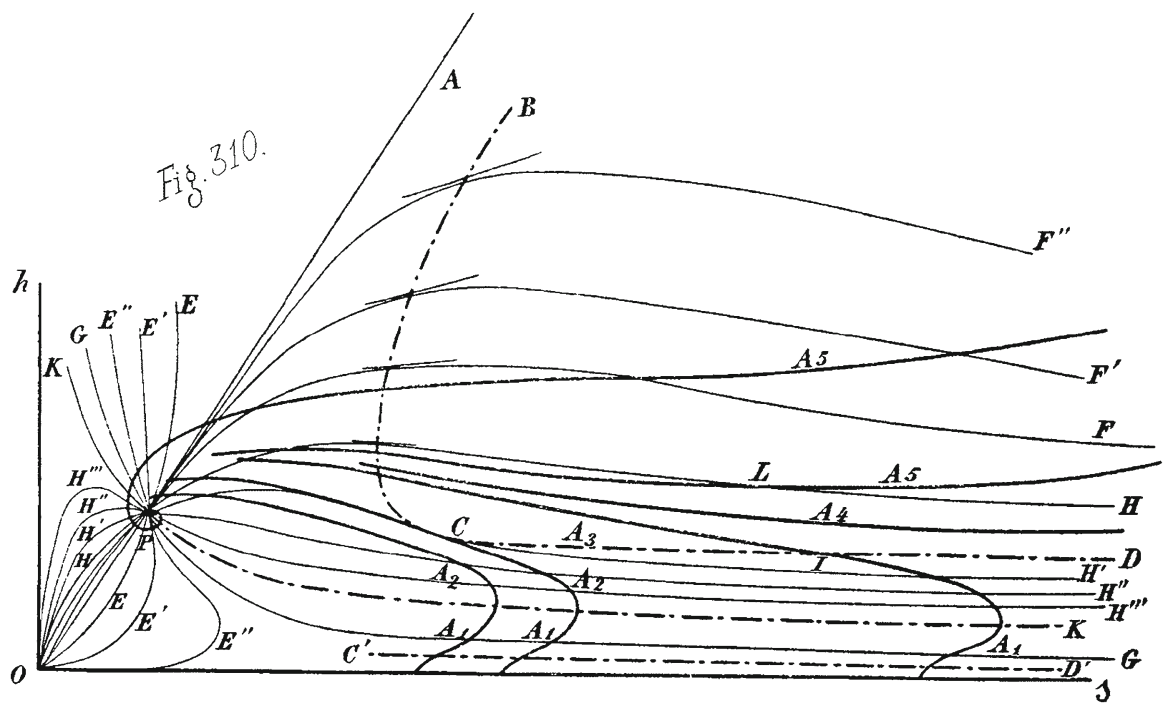

Fig. 15 An asymptotic point appearing in a hydraulic problem (Massau 1878-1887, Livre VI, pl. 4)

The construction of the integral curves from isoclines is another way of studying globally a differential equation. In contrast to Poincaré's abstract approach, Massau's diagram both gives a global description and a local description of the curves. This diagram is both an instrument of numerical calculation-the ordinates of a particular integral curve can be measured with an accuracy sufficient for the engineer's needs - and a heuristic tool for discovering properties of the differential equation.

For example, Massau applies this technique to hydraulics in studying the permanent motion of water flowing in a canal. He is interested in the variations of depth depending on the length of the canal, in the case of a rectangular section the width of which is growing uniformly. The differential equation to be solved is very complicated. With his elaborate graphical technique, Massau constructs isoclines (Fig. 15) and studies the behavior of the integral curves. He discovers that there is what he calls an "asymptotic point" $\mathrm{P}$ : the integral curves approaching from $\mathrm{P}$ are turning indefinitely around it.

Massau then develops a theoretical study of singular points from isoclines. For a differential equation $F\left(x, y, y^{\prime}\right)=0$, he considers the isoclines $F(x, y, \alpha)=0$ as the projections on the plane $(x, y)$ of the contour lines of the surface of equation $F(x, y, z)=0$, and the integral curves as the projections of certain curves drawn on this surface. By geometric reasoning in this three-dimensional framework, Massau finds the same results as Poincaré concerning the singular points, but in a very different manner.

He starts with the case where isoclines are convergent straight lines. In the general case, when isoclines pass by the same point, Massau studies the integral curves around this point by replacing the isoclines by their tangents. A singular points is always called a "focus". The special case we call "focus" today is the only one to receive a particular name, that of "asymptotic point". Massau determines very carefully the various 

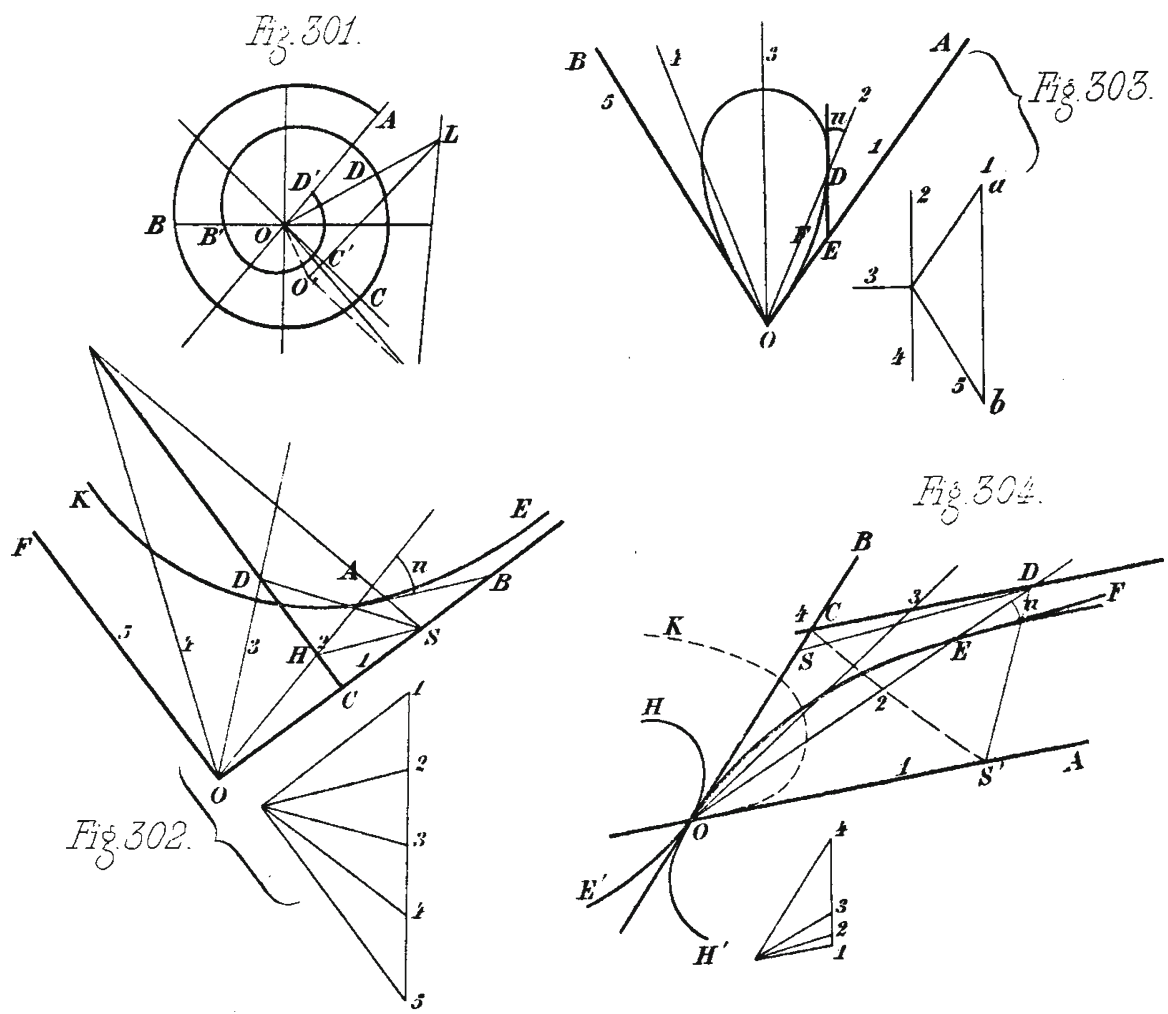

Fig. 16 Classification of singular points by Massau (1878-1887, Livre VI, pl. 4)

possible positions around a focus by considering the number of straight-line solutions passing through this point (Fig. 16).

To give an example of Massau's writing style, let us take the first case (Massau's Fig. 301) in which there is no straight-line solution. Massau says:

Suppose that, by varying $\alpha$ in all states of magnitude, we find that the isocline turns around the origin by taking every imaginable direction, and suppose that all these isoclines are cut by integral curves. If we start from any point A, we find an integral ABCD turning around the origin; it will be exceptionally closed. Let us follow the integral in a direction such as after a turn we are closer to the origin; we find an infinite number of similar turns; the integral curve gets indefinitely closer to the origin without being able to ever reach it. ${ }^{21}$

\footnotetext{
21 “Supposons qu'en faisant varier $\alpha$ par tous les états de grandeur, on trouve que la ligne isocline tourne autour de l'origine en prenant toutes les directions imaginables; supposons que toutes ces lignes isoclines soient coupées par les éléments d'intégrales. Si on part d'un point quelconque A, on trouvera une intégrale $\mathrm{ABCD}$ tournant autour de l'origine; elle ne sera fermée qu'exceptionnellement. Suivons l'intégrale dans un sens tel qu'après une spire on se rapproche de l'origine; on trouve une infinité de spires semblables; l'intégrale se rapproche indéfiniment de l'origine sans pouvoir jamais l'atteindre" (Massau 1878-1887, Livre VI, pp. 513-514).
} 
We see that Massau's style, strongly relying on the diagram, is similar to Poincaré's one. In Massau's reasoning, the isoclines play the same role as Poincaré's arcs without contact to guide the path of integral curves. In the quoted passage, Massau treats the case of focuses, including the exceptional case of centers. Other diagrams illustrate the case of saddles (Massau's Fig. 302) and the case of nodes (Massau's Figs. 303 and 304).

In using a graphical technique developed at first as a simple technique of numerical calculation, Massau succeeds also in a qualitative study, the purpose of which is the global layout of the integral curves and the description of their properties. He writes for example:

The graphic integration of differential equations also leads to useful results; we have shown by some examples [...] that we could integrate by geometry equations that are very much resistant to analytical methods. ${ }^{22}$

Knowing that Massau published his Book VI in 1887, is it possible that he had previously read Poincaré's memoir and that he was inspired in it? It is not very probable because, in fact, Massau had already presented a first version of his Book VI on December 3, 1877, at the Charleroi section of the Association of the engineers of Ghent university, as is shown by the monthly report of this association. Further, the vocabulary, the notations and the demonstrations used by Massau are clearly different from those of Poincaré. In particular, Massau constantly works with the isoclines, a notion about which Poincaré never speaks. Finally, Massau, who quotes many people whose work is related to his, never quotes Poincaré.

Clearly, Massau and Zhukovsky are part of a geometric tradition that survived since the beginning of Calculus within engineering and applied mathematics circles. In this tradition one kept on constructing equations with graphical computation and mechanical devices, as theoretical mathematicians came to prefer the analytical approach. In our story, it is interesting to notice the existence of these two currents without an apparent link between them, the one among academic mathematicians, the other among engineers, with similar results that have been rediscovered several times independently. In these two currents, the role of diagrams is very different. In Poincaré's abstract and theoretical approach the diagram - a freehand creation directly concretizing his visual thinking — can guide the reasoning in a topological manner or can serve to summarize an analytical study by a graphic synthesis (as in the five examples we have seen). For Massau, the diagram comes at first as an instrument of calculation. Graphical calculation allows the realization of a very accurate diagram, both locally and globally, and with a high heuristic value, which serves as a starting point for the reasoning. The family of isoclines gives here a new global picture of a differential equation, complementary to the bundle of integral curves.

\footnotetext{
22 "L'intégration graphique des équations différentielles conduit aussi à des résultats utiles; nous avons montré par des exemples [...] que l'on pouvait par la géométrie intégrer des équations qui résistent assez bien aux méthodes analytiques" (Massau 1889, p. 435).
} 


\section{Conclusion}

Philosophers have extensively studied simple diagrams, close to the foundations of mathematics. Intimately connected with definitions and axioms, such diagrams can then be used to specify the meaning of primitive objects and to fill some logical gaps of the theory, so that they actually play an inferential role in the reasoning. The case of differential equations seems somewhat different, because the objects of this theory, obtained after long and complex theoretical constructions, are far away from the primitive objects of mathematics. Moreover, differential equations were for three centuries at the heart of the essential tension between geometry and analysis. What is a solution of a differential equation? There is no definite answer. It is at the same time a curve, a motion, an algebraic equation, an infinite series, an algorithm of approximation, and so on. In this multiform context, some mathematicians (Euler, Cauchy, Lipschitz, etc.) tackled the problem of integration of differential equations in a purely analytical way, denying any reference to geometry and refraining from drawing diagrams. Others (Riccati, Poincaré, Massau, etc.) cultivated geometric vision and nourished their intuition by numerous diagrams, physical or mental. Certainly, we know that we can always translate geometrical statements into algebraical language, but the fact that the latter line of mathematicians achieved results the former line did not seems to prove that the use of diagrams played a key role, a role not simply reducible to a matter of presentation or style.

In our study, we had the opportunity to explore diagrams with various functions within mathematical discourse: formulating the equation using Leibnizian differentials, solving the equation as the result of a graphical algorithm of construction or of the use of a mechanical instrument, furnishing a geometric understanding of the behavior of solutions, pointing the way to theoretical insights, and so on. Beyond these functions, we met two major types of diagrams: on the one hand, quantitative and physically accurate diagrams, obtained by intricate numerical and graphical techniques; on the other hand, qualitative and topological diagrams, which can remain mental or can be roughly drawn freehand. The diagrams of the first type are most often used to translate geometrically, as faithful as possible, analytical or numerical results, in order to represent a given situation better, to understand it, and to provide a heuristic tool for further discoveries. The diagrams of the second type contribute to the development of geometric intuition, provide psychological aid to reasoning, are used to control analytical investigation, and also stimulate discovery, but in another way. Moreover, these diagrams bring invaluable help in the writing of demonstrations, by allowing compose short and understandable texts. In the theory of differential equations, it would certainly be possible to give proofs completely independent of the diagrams, but these proofs would be very long and tedious. So diagrams contribute by providing cognitive foundations instead of logical foundations for the theory, and by underlying the conception of proofs that not only convince, but also explain.

In the examples that I have detailed, it is difficult to pinpoint precisely which role diagrams played in the discovery of new results. Indeed, the texts that I have analyzed are expository texts, and we definitely know that in mathematics, the final form of proofs written for the public does not always accurately reflect the mental steps gone through by the researcher during the discovery process. It is also difficult to determine 
the extent to which we could, regarding differential equations, speak of "diagrammatic reasoning" in the same sense that this type of proof, intimately mixing diagrams and discursive text, was in evidence in Euclid's Elements (Mumma 2008, 2009). Indeed, in Euclid's time, there is no alternative text to the Elements where there is no use of diagrams. On the contrary, in the case of differential equations, even if it is true that some mathematicians obtain their results originally by relying strongly on diagrams, the same mathematicians are aware that they could do without them in presenting their results, and other mathematicians almost immediately write treatises containing the same results, but presented in a much more discursive manner. For example, in chapter X of the third volume of his Traité d'analyse (1896, pp. 228-252), Picard appropriates in his own style the first six chapters of Poincaré's 1881-1882 memoir on curves defined by differential equations. Where Poincaré gave 23 diagrams, he keeps only 2. It is interesting to note that Picard does not completely eliminate diagrams, as if, nonetheless, a minimum of geometric representation remained necessary for a global perception of the complex situation studied. This extreme case seems to confirm the important and irreducible role of visual thinking in the field of differential equations. In this part of mathematics, our confidence in analytical proofs comes largely from the fact that they are consistent with what we see on diagrams. Knowledge is there constructed by a subtle game between intuition, experimentation and abstract analytical theory, where visual and discursive thinking are constantly interacting.

Through this brief overview, I tried to sketch an initial study on the role of diagrams in the development of theory of differential equations, and to provide some historical landmarks in this subject. Thereby I hope to draw philosophers' attention to the potential of this rich and complex theory to deepen our understanding of visual thinking and diagrammatic reasoning in mathematics if examined more closely.

Acknowledgments I thank Marco Panza and three anonymous referees for their valuable suggestions and remarks, which allowed me to improve in a significant way the first version of the paper. I thank also John Mumma who has read through my text with great care to vet my English.

\section{References}

Agnesi, M. G. (1748). Instituzioni analitiche ad uso della gioventu' italiana (Vol. II). Milano: Nella Regia-Ducal Corte.

Andersson, K. G. (1994). Poincaré's discovery of homoclinic points. Archive for History of Exact Sciences, 48, 133-147.

Archibald, T. (2003). Differential equations: A historical overview to circa 1900. In H. N. Jahnke (Ed.), A history of analysis (pp. 325-353). Providence (Rhode Island): American Mathematical Society.

Arnold, V. (1974). Équations différentielles ordinaires. Moscou: Mir.

Barrow-Green, J. (1997). Poincaré and the three body problem. Providence (Rhode Island): American Mathematical Society.

Bernoulli, J. (1694). Modus generalis construendi omnes æquationes differentiales primi gradus. Acta Eruditorum, November, 435-437.

Boole, G. (1859). A treatise on differential equations. London: Macmillan.

Bos, H. J. M. (1988). Tractional motion and the legitimation of transcendental curves. Centaurus, 31, 9-62. Bottazzini, U. (2000). Poincaré, philosophe et mathématicien. Paris: Pour la Science.

Bush, V. (1931). The differential analyser. A new machine for solving differential equations. Journal of the Franklin Institute, 212, 447-488. 
Caparrini, S. (2006). On the common origin of some of the works on the geometrical interpretation of complex numbers. In K. Williams (Ed.), Two cultures. Essays in honour of David Speiser (pp. 139151). Basel: Birkhauser.

Carnot, L. N. M. (1803). Géométrie de position. Paris: Duprat.

Cauchy, A.-L. (1981). Équations différentielles ordinaires. Cours inédit (fragment). Paris: Études vivantes; New York: Johnson Reprint Corporation.

Chabert, J.-L., \& Dahan Dalmedico, A. (1992). Les idées nouvelles de Poincaré. In A. Dahan Dalmedico, J.-L. Chabert, \& K. Chemla (Eds.), Chaos et déterminisme. Paris: Seuil.

de Bougainville, L.-A. (1756). Traité du calcul intégral pour servir de suite à l'Analyse des infiniment petits de M. le marquis de l'Hopital. Seconde partie. Paris: Guérin \& Delatour.

de L'Hospital, G.-F. (1696). Analyse des infiniments petits pour l'intelligence des lignes courbes. Paris: Imprimerie Royale.

Dieudonné, J. (1964). Algèbre linéaire et géométrie élémentaire. Paris: Hermann.

Dobrovolski, V. A. (1972). Sur l'histoire de la classification des points singuliers des équations différentielles. Revue d'Histoire Des Sciences, 25, 3-11.

Euler, L. (1768-1769). Institutiones calculi integralis (Vols. I, II). Petropoli: Impensis Academiæ Imperialis Scientiarum.

Giaquinto, M. (1994). Epistemology of visual thinking in elementary real analysis. The British Journal for the Philosophy of Science, 45, 789-813.

Gilain, C. (1991). La théorie qualitative de Poincaré et le problème de l'intégration des équations différentielles. Cahiers d'Histoire et de Philosophie Des Sciences, 34, 215-242.

Gilain, C. (1994). Ordinary differential equations. In I. Grattan-Guinness (Ed.), Companion encyclopedia of the history and philosophy of the mathematical sciences (Vol. 1, pp. 440-451). London, New York: Routledge.

Guicciardini, N. (1994). Three traditions in the calculus: Newton, Leibniz and Lagrange. In I. Grattan-Guinness (Ed.), Companion encyclopedia of the history and philosophy of the mathematical sciences (Vol. 1, pp. 308-317). London, New York: Routledge.

Hill, G. W. (1878). Researches in the lunar theory. American Journal of Mathematics, 1, 5-26, 129-147, 245-260.

Israel, G., \& Menghini, M. (1998). The "essential tension" at work in qualitative analysis: A case study of the opposite points of view of Poincaré and Enriques on the relationships between analysis and geometry. Historia Mathematica, 25, 379-411.

Kolmogorov, A. N., \& Yushkevich, A. P. (Eds.). (1998). Mathematics of the 19th century (Vol. 3). Basel: Birkhäuser (Part 2: "Ordinary Differential Equations", pp. 83-196).

Lacroix, S.-F. (1798). Traité du calcul différentiel et du calcul intégral (Vol. 2). Paris: Duprat.

Lagrange, J.-L. (1806). Leçons sur le calcul des fonctions, nouvelle édition revue, corrigée et augmentée par l'Auteur. Paris: Courcier.

Laplace, P.-S. (1891-1893). Euvres complètes (Vols. 8, 9). Paris: Gauthier-Villars.

Lipschitz, R. (1880). Lehrbuch der Analysis. II. Differential- und Integral-Rechnung. Bonn: Cohen.

Longo, G. (1997). Géométrie, mouvement, espace: cognition et mathématiques. Intellectica, 25, 195-218.

Mancosu, P. (2005). Visualization in logic and mathematics. In P. Mancosu, K. F. Jorgensen, \& S. A. Pedersen (Eds.), Visualization, explanation and reasoning styles in mathematics (pp. 1330). Dordrecht: Springer.

Manders, K. (2008). The Euclidean diagram (1995). In P. Mancosu (Ed.), The philosophy of mathematical practice (pp. 80-133). Oxford: Oxford University Press.

Manfredi, G. (1707). De constructione aquationum differentialium primi gradus. Bononiæ: Typis Constantini Pisarri.

Massau, J. (1878-1887). Mémoire sur l'intégration graphique et ses applications. Annales des Ingénieurs Sortis des Écoles Spéciales de Gand, 2, 13-55, 203-281; 7, 53-132; 10, 1-535.

Massau, J. (1889). Appendice au mémoire sur l'intégration graphique et ses applications. Annales Des Ingénieurs Sortis Des Écoles Spéciales de Gand, 12, 185-443.

Moigno, F.-N.-M. (1844). Leçons de calcul différentiel et de calcul intégral rédigées d'après les méthodes et les ouvrages publiés ou inédits de M. A.-L. Cauchy (Vol. 2). Paris: Bachelier.

Mumma, J. (2008). Ensuring generality in Euclid's diagrammatic arguments. In G. Stapleton, J. Howse, \& J. Lee (Eds.), Diagrammatic representation and inference, 5th international conference, diagrams 2008, Herrsching, Germany, September 19-21, 2008. Dordrecht: Springer.

Mumma, J. (2009). Proofs, pictures, and Euclid. Synthese. doi:10.1007/s11229-009-9509-9. 
Painlevé, P., \& Vessiot, É. (1910). Équations différentielles ordinaires. In J. Molk (Ed.) Encyclopédie des sciences mathématiques pures et appliquées, Tome II (Vol. 3, fasc. 1). Paris: Gauthier-Villars.

Panza, M. (2007). The twofold role of diagrams in Euclid's plane geometry. Hyper Articles en Ligne. http://hal.archives-ouvertes.fr/hal-00192165/fr/.

Picard, É. (1893-1896). Traité d'analyse (Vols. 2, 3). Paris: Gauthier-Villars.

Poincaré, H. (1881). Mémoire sur les courbes définies par une équation différentielle. Journal de Mathématiques Pures et Appliquées (3), 7, 375-422.

Poincaré, H. (1882). Mémoire sur les courbes définies par une équation différentielle. Journal de Mathématiques Pures et Appliquées (3), 8, 251-296.

Poincaré, H. (1885). Mémoire sur les courbes définies par une équation différentielle. Journal de Mathématiques Pures et Appliquées (4), 1, 167-244.

Poincaré, H. (1886). Mémoire sur les courbes définies par une équation différentielle. Journal de Mathématiques Pures et Appliquées, (4), 2, 151-217.

Poincaré, H. (1892). Les méthodes nouvelles de la mécanique céleste (Vol. 1). Paris: Gauthier-Villars.

Poincaré, H. (1895). Analysis situs. Journal de l'École polytechnique, IIe série, Premier cahier.

Poincaré, H. (1899). Les méthodes nouvelles de la mécanique céleste (Vol. 3). Paris: Gauthier-Villars.

Riccati, V. (1752). Du usu motus tractorii in constructione aquationum différentialium. Bononiæ: Ex Typographia Lælii a Vulpe.

Shin, S.-J. (1994). The logical status of diagrams. Cambridge: Cambridge University Press.

Tournès, D. (2003a). L'intégration graphique des équations différentielles ordinaires. Historia Mathematica, 30, 457-493.

Tournès, D. (2003b). Junius Massau et l'intégration graphique. Revue d'Histoire Des Mathématiques, 9, 181-252.

Tournès, D. (2009). La construction tractionnelle des équations différentielles. Paris: Blanchard. 